Pickering et al.

\title{
New Early Pleistocene Hominin Teeth from the Swartkrans Formation, South Africa
}

\author{
Travis Rayne Pickering*1,2,3 \\ Jason L. Heaton ${ }^{2,3,4}$ \\ Morris B. Sutton ${ }^{5}$ \\ Ron J. Clarke² \\ Kathleen Kuman ${ }^{5}$ \\ Jess Hutton Senjem ${ }^{1}$ \\ C.K. Brain ${ }^{3}$
}

1. Department of Anthropology, University of Wisconsin, Madison, Wisconsin, 53706, USA

2. Evolutionary Studies Institute, University of the Witwatersrand, Private Bag 3, WITS 2050, South Africa

3. Plio-Pleistocene Palaeontology Section, Department of Vertebrates, Ditsong National Museum of Natural History (Transvaal Museum), Pretoria, South Africa

4. Department of Biology, Birmingham-Southern College, Birmingham, Alabama, 35245, USA

5. School of Geography, Archaeology and Environmental Studies, University of the Witwatersrand, Private Bag 3, WITS 2050, South Africa

*Corresponding author TR Pickering, Phone: USA (608) 262-5818; Fax: USA (608) 265-4216;

E-mail: tpickering@wisc.edu 
Pickering et al.

\begin{abstract}
We describe 14 hominin teeth and tooth fragments excavated recently from Swartkrans Cave (South Africa). The fossils derive from Members 1 (Lower Bank) and 3, from the Member 2/3 interface and from two deposits not yet assigned to member (the "Talus Cone Deposit" and "Underground North Excavation" [UNE]) of the Swartkrans Formation, and include the first hominin fossil from the UNE, the two smallest Paranthropus robustus deciduous maxillary second molars in the entire hominin fossil record, and one of the smallest P. robustus permanent maxillary second molars from Swartkrans. The small permanent molar is accompanied by another tooth from a different individual but from the same stratigraphic level of the Swartkrans Formation; this second tooth is among (if not) the largest P. robustus permanent maxillary first molars known from anywhere-lending credence to assertions that degrees of body size sexual dimorphism previously ascribed to this species may be underestimated. It is more equivocal whether this evidence also supports hypotheses proposing that $P$. robustus assemblages from Swartkrans (as well as those from other South African cave sites) formed through the taphonomically biasing actions of large carnivores.
\end{abstract}

Keywords: Swartkrans Formation; Paranthropus robustus; dentition; body size sexual dimorphism; carnivore-collecting hypothesis 
Pickering et al.

\section{Introduction}

Swartkrans Cave (Gauteng, South Africa) continues to yield an important early Pleistocene record of hominin evolution that includes fossils of Paranthropus (Australopithecus) robustus and early Homo (e.g., Broom, 1949; Broom and Robinson, 1949, 1950, 1952; Clarke et al., 1970; Clarke and Howell, 1972; Clarke, 1977; Brain, 1981; Brain et al., 1988; Grine, 1989, 1993; Susman 1989, 1993; Sutton et al., 2009; Pickering et al., 2012), as well as abundant archaeological traces (i.e., stone tools, butchered animal bones, purported bone tools and bones that might have been burned in hominin-controlled fires) created by one or both of these taxa (e.g., Brain, 1981, 1993a; Brain et al., 1988; Backwell and d'Errico, 2003; Pickering et al., 2004, 2005, 2007, 2008) (Figure 1).

Excavations conducted by the Swartkrans Paleoanthropological Research Project (SPRP) since 2005 have generated large samples of non-hominin vertebrate fossils and artifacts. These extensive paleoanthropological samples, derived from several areas of the site and from various members of the Swartkrans Formation, are still under analysis, but here we provide descriptions of all previously unreported hominin teeth and tooth fragments (14 in total) recovered by the SPRP, augmenting the $400+$ hominin specimens already recovered and described from Swartkrans. 
Pickering et al.

\section{Geochronological and paleoanthropological contexts of the newly described fossils}

Swartkrans Cave is located $\sim 40 \mathrm{~km}$ northwest of Johannesburg in the $466 \mathrm{~km}^{2}$ UNESCO World Heritage Site that, with its multiple fossiliferous caves, is designated as the "Cradle of Humankind"

(Figure 1). Swartkrans developed as a phreatic maze cave within the impure dolomitic limestone of the Chunniespoort Group (Palmer, 1991; Brain, 1993b). It is likely that the cave first opened to the ground surface sometime in the early Pleistocene, when it then began to admit materials of the Swartkrans Formation (Brain, 1976, 1993b; Butzer, 1976).

Starting with Member 1, the five sequential members of the Swartkrans Formation are separated by erosional discontinuities. The three subunits of Member 1 are the Lower Bank (LB), the Lower Bank East Extension (LBEE) and the Hanging Remnant (HR) (Brain, 1993b; Sutton et al., 2009; Pickering et al., 2012). The LB and LBEE of Member 1 are indistinguishable depositionally and sedimentologically. They form a single infill, and are only classified separately because the eastern portion of this depositional body was recognized by Sutton et al. (2009) long after the Swartkrans Formation was re-codified by Brain (1993b). The soils of the LB/LBEE were admitted into Swartkrans via a shaft (or shafts) that opened to the ground surface above. Eventually this surfacederived material—characterized by sandy silt, with occasional clasts of subangular dolomite, chert and quartz (4 to $120 \mathrm{~mm}$ in size), as well as numerous artifacts and fossils-filled most of the underground opening, banking against the north wall of the cavern. The entryway (or entryways) for the LB/LBEE sediments was/were eventually choked by sediment and new shafts then opened along the north wall of the cave, admitting a subsequent cycle of materials. This younger, heavily calcified deposit—originally referred to as the "pink breccia" (Robinson, 1952; Brain and Robinson, 1953; Brain, 1958) but now designated as the HR—consists of surface-derived soils and sandy sediment, characterized by stony inclusions that include blocks of dolomite and chert roof-spall (Brain, 1958). Fossils are abundant in the HR, but the breccia has yielded no stone tools and only 
Pickering et al.

two purported bone tools. The HR sediments eventually completely filled their points of entry. Uranium-lead (U-Pb)-dated flowstones, which bound the lower and upper reaches of Member 1 (in toto), provide a bracketed age of $2.249 \pm 0.077-1.706 \pm 0.069$ Ma (reported uncertainties at twosigma) (Pickering et al., 2011) for the member; this range is in broad agreement with previous estimates of the member's age based on faunal data (e.g., Vrba, 1985; Brain, 1993b; Churcher and Watson, 1993) and with more recent ones based on cosmogenic nuclide burial dating (i.e., average age $=1.99 \pm 0.19 \mathrm{Ma}, \pm 1$ s.e.) (Gibbon et al., 2014).

A gap, several meters in width, eventually eroded between the base of the HR and the top of the LB. New openings to the ground surface then admitted the Member 2 sediments (Brain, 1993b). Except for a thin remaining skin of water-lain, stratified sediments that adhere to the northwest wall of the cave, most of Member 2 was removed long ago by scientific excavations at Swartkrans. Generally, the Member 2 "brown breccia” (Brain, 1958) is easily distinguished by its lack of stony inclusions any larger than gravel (a few pieces of dolomite roof-spall excepted); fallen blocks of calcified "pink breccia" from the HR are sometimes observed in the Member 2 matrix. Member 2 has also yielded abundant fossils, stone tools and purported bone artifacts. Pickering et al.'s (2011) U-Pb-derived $1.706 \pm 0.069 \mathrm{Ma}$ date of a flowstone that separates the HR and the overlying sediments of Member 2 along the cave's northwest wall provides a maximum age for the latter unit. No other reliable radiometric ages are currently available for Member 2, but faunal data suggest an age of $\sim 1.5 \mathrm{Ma}$ for the infill (e.g., Vrba, 1985; Brain, 1993b; Churcher and Watson, 1993).

The Member 3 sediments occur in a gully that was eroded into Member 1 and 2 deposits along the west wall of the cave. The deposit contains clasts of predominantly angular to sub-angular rock, including dolomite (4 to $120 \mathrm{~mm}$ in size). The deeper portions of the gully include a few large to boulder-sized clasts of dolomite, some of which may be spall from the original cave roof. Member 3 


\section{Pickering et al.}

is rich in fossils, artifacts and burned bones. Early, fauna-derived estimates placed the unit's age at 1.0 Ma (e.g., Vrba, 1985; Brain, 1993b; Churcher and Watson, 1993), with more recent cosmogenic nuclide burial dating analysis refining that age to $0.96 \pm 0.09 \mathrm{Ma}$ (Gibbon et al., 2014).

Member 4 is an extensive colluvial deposit that was not conducive to the preservation of bone. It occupies an area of $\sim 62 \mathrm{~m}^{2}$ on the cave's surface and spreads underground, covering the outer surface of a large talus cone that extends $>10$ m deeper than the highpoint of the Swartkrans surface excavation. The Member 4 sediments are dark reddish-brown, loose, non-calcified silty sand, with abundant small to large clasts of angular dolomite, as well as abundant Middle Stone Age (MSA) lithic artifacts. The Member 4 colluvium is of variable thickness, ranging from $\sim 120 \mathrm{~cm}$ at the site surface to $10-15 \mathrm{~cm}$ underground, where it covers the base of the talus cone's north face. Portions of the unit superimpose a now-fractured speleothem, which was dated using uraniumthorium (U-Th) methods to $110,000 \pm 1,980$ years old (Sutton et al., 2009), setting a maximum age for the deposit.

Member 4 and the U-Th-dated speleothem overlie a massive, recently recognized deposit designated provisionally as the "Talus Cone Deposit" (TCD) but not yet formally categorized within the Swartkrans Formation member system (Sutton et al., 2009) (Figure 1). The TCD, in turn, overlies the LBEE. The TCD is characterized by dark red, non-calcified silty sand, with small to medium sized $(10-25 \mathrm{~cm})$ clasts of angular and subangular dolomite and contains an abundance of fossils but no MSA stone artifacts deeper than its outer $20 \mathrm{~cm}$. The presence of $P$. robustus fossils in the TCD corroborates the inference based on superposition that it is of greater age (i.e., probably early Pleistocene) than the overlying flowstone and MSA artifact-bearing unit (Sutton et al., 2009). 


\section{Pickering et al.}

The remaining area of the Swartkrans Formation to have yielded fossilized (presumably early Pleistocene) hominin remains is an expansive underground excavation area $\sim 5 \mathrm{~m} \mathrm{NW}$ of the three talus cone deposits in the NE corner of the site, which are described above as the Member 4 MSA, the TCD and the LBEE (Figure 1). This newly recognized fossiliferous area, referred to informally as the "Underground North Excavation" (UNE), extends laterally north 25 m into the Swartkrans hillside following a northward dipping slope of $2-3 \mathrm{~m}$. Brain cleared this area of rubble during his 1979 - 1986 excavations at Swartkrans; subsequently, the SPRP conducted the first controlled excavations in the UNE beginning in 2008. These more recent excavations revealed that the UNE is a highly disturbed portion of Swartkrans, where early- to mid-20 th $c e n t u r y$ lime-miners created a flat platform in order to facilitate their extractive activities at the site. Four square meters of the UNE were excavated through a dark red, non-calcified, loosely consolidated sandy soil, with small to medium sized $(10-25 \mathrm{~cm})$ clasts of angular and subangular dolomite. Upon reaching a depth of $50-60 \mathrm{~cm}$ in these four squares, we observed a distinct stratigraphic change to a gray colored matrix composed of crushed dolomite rock and a dearth of finer sediment. Matches, fragments of metal and other waste deposited by early miners are common in this gray stratum. Our attempts to dig through this disturbed and very deep level forced us to expand our excavation in the UNE laterally to include four additional square meters. Our excavations in the UNE are also confounded by the depth and complexity of this artificially constructed "floor," which comprises more crushed dolomite resting on a layer of small dolomite clasts and even larger dolomite blocks at the deepest levels reached; we are currently at a depth of $2.5 \mathrm{~m}$ below the starting surface of the UNE excavation and have yet to break through this thick deposit of miners' rubble.

The miners' rubble level is devoid of Pleistocene artifacts and fossils, but the overlying red layer includes heavily mineralized bones, as well as non-fossilized, modern bones (the latter mostly, lagomorph and canid remains). Sedimentological analyses of the red layer are ongoing, but initial 
Pickering et al.

results indicate they likely derive from the P. robustus-bearing TCD. In order to create an access tunnel, miners long ago removed a section of the north face of the talus cone in which the TCD is positioned. Based on the principle of least-effort, we suspect that the miners shifted the sediments they removed from the talus cone across the short distance to the UNE.

The 14 hominin fossils described in this paper are newly recovered by the SPRP from the LB, the TCD, Member 3, and the UNE. In addition, two of the fossils derive from coordinates along the interface of Member 2 and Member 3, where precise stratigraphic separation between materials is ambiguous.

\section{Materials and methods}

\section{Field methods}

During the course of his 1979 - 1986 excavations, C.K. Brain established a metal square meter grid over the Swartkrans surface deposits (Figure 1). In 2005, the SPRP re-established this grid using an EDM Total Station, and in the course of work also reinitiated excavations in Member 1 (LB), at the interface of Member 2/Member 3, in Member 3, in Member 4 (as well as into the TCD and Member 1 LBEE deposits that underlie it), in Member 5 (not discussed here) and in the UNE. For all work in non-calcified sediments, the SPRP excavated each square by quadrant $(50 \mathrm{~cm} \times 50 \mathrm{~cm})$ at $5 \mathrm{~cm}$ and $10 \mathrm{~cm}$ depths (in some rare, but unavoidable cases, highly localized sedimentary instability forced us to excavate in levels that exceeded $10 \mathrm{~cm}$ ). Each quadrant level was excavated separately and then sieved using a $5 \mathrm{~mm}$ mesh over a $2 \mathrm{~mm}$ mesh screen. The material from the $5 \mathrm{~mm}$ mesh was then wet sieved. The $2-5 \mathrm{~mm}$ fraction material recovered from wet sieving was sorted in order to ensure the collection of small bone and tooth fragments of macrovertebrates, microfaunal remains and stone artifact chips. 
Pickering et al.

\section{Fossil analyses}

Each hominin fossil was examined using a low-power binocular microscope and, when possible, measurements were taken with a Paleo-Tech Concepts ${ }^{\mathrm{TM}}$ Hillson-Fitzgerald dental caliper.

Standard gross tooth crown measurements (i.e., mesiodistal and bucco/labiolingual diameters) were taken to the nearest tenth of a millimeter (e.g., Robinson, 1956; Tobias, 1967; Grine, 1984;

Wood, 1991). When possible, we measured the cervico-occlusal height (measured in the vertical plane) and labio/buccolingual breadth (measured in the horizontal plane) of interproximal contact facets on dental specimens. When possible, we used methods described by White et al. (2006) in order to measure enamel thickness along natural fracture surfaces for relevant postcanine teeth. Two of the postcanine specimens for which we were able to obtain enamel thicknesses are not assignable as maxillary or mandibular teeth, nor can either be placed definitively as premolar or molar; thus, we were not able to distinguish at which cusp the fracture surface of each occurs. We were, however, able to ensure that measurement of the enamel thickness of each of these two specimens was taken along a radial section, "i.e., on sections that were considered to approximately exhibit local minimal distances from the enamel-dentine junction (EDJ) to the outer enamel surface" (White et al., 2006: Supplementary Discussion 2).

Taxonomic determinations of teeth were based on various features used previously to differentiate Australopithecus, Paranthropus and early Homo dentitions, including, but not limited to, cusp shape, occlusal surface area, and occlusal wear pattern (e.g., Robinson, 1956; Tobias, 1965, 1967; Clarke, 1977; Howell, 1978; Wood and Abbott, 1983; Wood et al., 1983; Wood and Engleman, 1988; Grine, 1984, 1985, 1989, 2005; Suwa et al., 1994, 1996). The newly described fossils were compared to original fossils and casts of previously described fossil hominin teeth listed in Table 1. Additional comparative data are from Wood (1991) and Moggi-Cecchi et al. $(2006,2010)$ and courtesy of Jacopo Moggi-Cecchi. 
Pickering et al. (2012) provide information on the fossil cataloging system employed in this paper, using the prefixes SWT1/LB (for fossils from the Lower Bank of Member 1), SWT1/HR (for fossils from the Hanging Remnant of Member 1) and SWT-TC (for fossils from the "Talus Cone Deposit"). In addition, we add here three new prefixes to that system in order to denote fossils from the Member 2/Member 3 interface (SWT2/3), Member 3 (SWT3) and the "Underground North Excavation" (SWT-UNE).

\section{Results}

Table 2 lists the newly discovered hominin fossils from Swartkrans and provides their taxonomic assignments and excavation coordinates. Table 3 gives standard linear dimensions for meaningfully measurable specimens, along with comparative summary statistics for previously recovered specimens for each represented element. Descriptions of the new specimens are provided below, organized by geological position, starting with the Lower Bank of Member 1 . We also provide detailed justifications for taxonomic allocations of the new fossils, grouped by tooth type and starting with permanent maxillary lateral incisors. Abbreviations used: BL = buccolingual or buccolingually; $\mathrm{CEJ}$ = cementoenamel junction; $\mathrm{CO}$ = cervico-occlusal or cervico-occlusally; ICF = interproximal contact facet; LL = labiolingual or labiolingually; MD = mesiodistal or mesiodistally.

\section{Member 1 Lower Bank fossils}

SWT1/LB-17 (Figure 2c): This poorly preserved right permanent maxillary canine (RC1) includes a remnant of its root (maximum length on lingual side $=3.8 \mathrm{~mm}$ ), the lingual face (maximum crown height lingually $=5.8 \mathrm{~mm}$ ) and most of the mesial face of the enamel cap. The lingual half of the apical margin is covered by enamel. In addition to developmental pitting, heavy antemortem 


\section{Pickering et al.}

wear-including pitting and several very fine scratches that run subparallel to the specimen's long axis, along both marginal grooves -is apparent on these portions of intact enamel. With the tooth in anatomical position, the lingual enamel rim cants markedly distally. The distal face of the crown is delimited by a thin rim of enamel that runs along the CEJ, from which an intact stump of dentine projects apically. Labially, a short flange of ovorectangularly shaped enamel encroaches onto this dentine stump. Otherwise, the distal and labial enamel of the crown is missing, having been lost post-depositionally. The tuberculum is modestly developed; the remnants of the lingual marginal ridges are unremarkable, bounded by seemingly weakly developed marginal grooves. Meaningful standard crown measurements are unobtainable.

SWT1/LB-18 (Figure 2d; Table 3): This well-preserved, right permanent maxillary second incisor $\left(\mathrm{RI}^{2}\right)$ is nearly complete, lacking just the apex of its root. The preserved portion of the root measures $13.2 \mathrm{~mm}$ labially and $13.3 \mathrm{~mm}$ lingually in length from the CEJ to its superior termination. The root is thick MD from the CEJ superiorly, nearly to its superior termination, with a maximum MD root width of $5.0 \mathrm{~mm}$. The root is markedly thicker LL at its midpoint $(7.1 \mathrm{~mm})$ than at the CEJ $(6.1 \mathrm{~mm})$. The incisal surface of SWT/LB-18 is well-worn into a flat table consisting of exposed dentine, bounded by an unbroken rim of enamel that is roughly perpendicular to the long axis of the crown, but with a slight distolingual cant. The level of incisal marginal wear has largely obliterated the mesial and distal marginal ridges and grooves and reaches the incisal boundaries of both ICFs but does not extend to the tooth's moderately developed tuberculum (labial crown height $=6.2 \mathrm{~mm}$; lingual crown height $=4.8 \mathrm{~mm})$. The distal ICF $(\mathrm{LL}=3.0 \mathrm{~mm} ; \mathrm{CO}=1.8 \mathrm{~mm})$ is larger than the mesial ICF (LL = $3.1 \mathrm{~mm} ; \mathrm{CO}=1.6 \mathrm{~mm}$ ). The distal ICF is also dual-faceted, with a subtle ridge of enamel separating a larger, more incisally set surface from a smaller, more cervically placed demifacet. The low remnants of the marginal ridges suggest that they were only weakly developed. The labial 


\section{Pickering et al.}

surface of the crown evinces minor developmental pitting and a few miniscule antemortem scratches.

SWT1/LB-19 (Figure 2a; Table 3): The root of this complete, well-preserved, right deciduous maxillary central incisor ( $\left.\mathrm{Rdi}^{1}\right)$ is partially resorbed. From the CEJ to its superior termination, the root measures $7.5 \mathrm{~mm}$ in length labially and $9.1 \mathrm{~mm}$ lingually. The root is broad MD (maximum MD length $=6.2 \mathrm{~mm}$ ) relative to its flatness LL (maximum LL breadth $=4.0 \mathrm{~mm}$ ). The crown's incisal margin is worn into a flat table of exposed and highly polished dentine that slopes markedly in lingual and, especially, distal directions and is bounded by an extremely thin rim of enamel on its labial, lingual and distal faces. The mesial face of the crown is devoid of enamel and the mesial ICF $(\mathrm{LL}=3.9 \mathrm{~mm} ; \mathrm{CO}=3.2 \mathrm{~mm})$, spanning from the crown margin to the CEJ, is developed strongly into the surface of root at this position. The distal ICF has been almost completely obliterated by incisal wear, now only apparent as a microscopic (and un-measurable) indentation of the distal corner of the crown. Maximum crown heights labially and lingually occur at the crown's mesial corners and measure, respectively, $6.0 \mathrm{~mm}$ and $1.8 \mathrm{~mm}$; the labial crown surface bulges markedly mesially, just inferior to the CEJ. Two deep, close-set, subparallel scratches, which were incurred and subsequently polished during the antemortem phase, run in a cervico-mesial direction from the inciso-distal quadrant of the labial face; other minor, polished antemortem chips fringe the incisal margin. The labial surface also preserves evidence, including pits and crescent-shaped indentations, indicating that enamel formation was disrupted.

SWT1/LB-20 (Figure 3b; Table 3): The paracone, metacone and partial hypocone of this fragmentary left deciduous maxillary second molar $\left(\mathrm{Ldm}^{2}\right)$ are preserved. As evinced by its highly polished lingual margin, the rest of the tooth's crown was worn away antemortemly. However, the projected occlusal outline suggests that the tooth was originally four-cusped and is now missing its 


\section{Pickering et al.}

protocone. The occlusal surface is heavily worn, with complete exposure of polished dentine across a table that is rimmed by a thin margin of enamel, which, itself, is obliterated inferior to the mesiobuccal root. The buccal crown height inferior to the distobuccal root (i.e., maximum distal crown height) is $5.4 \mathrm{~mm}$. The differential crown heights of the mesial and distal occlusal margins gives the crown a heavily mesially sloping profile when viewed in buccal or lingual aspect. Minor developmental pitting is observable on the preserved portions of the crown. The distal ICF is large $(\mathrm{BL}=7.2 \mathrm{~mm})$, oval-shaped and meets the enamel rim occlusally $(3.5 \mathrm{~mm})$. The mesial ICF is obliterated but there are two small, serial indentations that are each roughly circular-segmental in form (the total combined BL span of these two features is $2.4 \mathrm{~mm}$ ) on the inferior surface of the mesiobuccal root (i.e., near the level of the eradicated CEJ). Superior to these indentations, the mesiobuccal root is scarred by six discrete gouges; the sourceof this taphonomic damage is unclear. The two preserved root segments are mostly resorbed.

\section{"Talus Cone Deposit" fossils}

SWT/TC-5 (Figure 3c; Table 3): This unerupted left permanent maxillary molar is a well-preserved, four-cusped crown, with a fairly prominent metaconule. The crown is small but because it is also moderately crenulated and rhombic in occlusal view, we diagnose the tooth as a second $\left(\mathrm{M}^{2}\right)$, rather than a first, upper molar $\left(\mathrm{M}^{1}\right)$. The central and mesial triangular fossae are deep and well-formed. The distal triangular fossa is also deep but with a fairly restricted surface area; as a result, the tips of the hypocone and metacone are closely spaced. All cusp tips are rounded and converge toward the well-developed transverse groove as they descend from the CEJ (with the buccal face more vertical than is the lingual face). The protocone height is $9.0 \mathrm{~mm}$, paracone height is $7.6 \mathrm{~mm}$, metacone height is $7.8 \mathrm{~mm}$ and hypocone height is $9.4 \mathrm{~mm}$. The lingual groove is in the form of a wide, inverted "V" (its vertex positioned halfway on the lingual crown face) that provides clear separation of the protocone and hypocone lingually. The buccal groove is much more subtle-broad 


\section{Pickering et al.}

and short, ascending only a third of the crown face. SWT/TC-5 lacks any trace of a Carabelli's complex. Although the specimen has suffered a recent elongated chip along the CEJ of its mesial face, the rest of the enamel line is perfectly preserved and indicates that the tooth roots had not formed at the time of the SWT/TC-5 individual's death (the open base of the crown is partially filled with red breccia matrix).

SWT/TC-2 is a previously described (Sutton et al., 2009) RM11 from the TCD. Like SWT/TC-5, SWTTC-2 is, by Swartkrans' standards (Robinson, 1956; Grine, 1993), a rather small maxillary molar. Both SWT/TC-5 and SWT/TC-2 do, however, fall comfortably within the metric range of, respectively, P. robustus $\mathrm{M}^{2} \mathrm{~s}$ and $\mathrm{M}^{1} \mathrm{~s}$ from Drimolen (Moggi-Cecchi et al., 2010) and also-as described above and in Sutton et al. (2009)—display typical P. robustus morphology (e.g., Robinson, 1956). The SWT/TC-2 $\mathrm{M}^{1}$ also lacks a distal ICF, indicating that the hominin to which it belonged did not have a fully erupted $\mathrm{M}^{2}$ at the time of its death. Last, considering the prevailing slope of sediments from which the two fossils were excavated, they came to rest in quite close proximity (Table 2; Sutton et al., 2009: 693, Table 2). Following from these observations-and in compliance with taphonomic parsimony-we suggest that SWT/TC-2 and SWT/TC-5 possibly derive from the same $P$. robustus individual.

SWT/TC-6 (Figure 4a): This postcanine tooth fragment has a maximum preserved crown height of $9.7 \mathrm{~mm}$ and the maximum length of its adhering root fragment is $2.6 \mathrm{~mm}$. Maximum enamel thickness is $2.7 \mathrm{~mm}$. Based on the following features, we tentatively identify SWT/TC-6 as a permanent mandibular fourth premolar $\left(\mathrm{P}_{4}\right)$ : the CEJ of the specimen shows pronounced curvature, its occlusal wear pattern matches that observed on some previously described Swartkrans $P$. robustus $\mathrm{P}_{4} \mathrm{~S}$ (cf. SK 9), plus the specimen preserves a well-developed (presumed) distal groove that 
Pickering et al.

is restricted to the occlusal third of the crown and that clearly separates the (presumed) buccal ridge and (presumed) distal lobe. The presumed distal face of the specimen preserves a fragment of an ICF. SWT/TC-6 does not refit to SWT/TC-3 (Sutton et al., 2009) or to SWT/TC-7 (described below), two other hominin postcanine tooth fragments excavated from the TCD.

SWT/TC-7 (Figure 4b): This postcanine tooth fragment has a maximum preserved crown height of $9.9 \mathrm{~mm}$ and the maximum length of its adhering root is $1.9 \mathrm{~mm}$. Maximum enamel thickness is 2.9 mm. SWT/TC-7 does not refit to SWT/TC-3 (Sutton et al., 2009) or to SWT/TC-6 (described above), two other hominin postcanine tooth fragments excavated from the TCD.

SWT/TC-8 (Figure 3d; Table 3): Although its roots are missing and the mesiobuccal half of its paracone is broken away, the crown of this large $\mathrm{RM}^{1}$ is otherwise beautifully preserved. Its occlusal surface is uncomplicated morphologically and worn very minimally, with no exposed dentine and only minor faceting of the cusps. The projected occlusal outline of SWT/TC-8 is roughly square, with a strongly developed distolingual lobe, which is separated from the mesiolingual quadrant of the crown by a long, prominent lingual groove that ascends roughly half of the crown's lingual face. All other developmental grooves (now filled by calcified sediment), except for the buccal groove, which is only slightly more than a mere inflection on the buccal crown face, are also strongly expressed. The metaconule is bisected MD by an accessory fissure. The oblique ridge is low and subtly developed, delimiting a relatively deep distal triangular fossa. The mesiolingual face of the protocone is marked by a conspicuous Carabelli's effect. Although the buccal face of the crown is more vertical than is its lingual face, all cusp tips are broad and blunt, bounded by weakly developed, centrally sloping cusp ridges: protocone height is $10.71 \mathrm{~mm}$, and hypocone height is $9.59 \mathrm{~mm}$ (paracone and metacone heights are unobtainable, as the former is largely missing and the CEJ superior to the latter is damaged). SWT/TC-8 lacks a distal ICF, but the 


\section{Pickering et al.}

preserved, lingual remnant of its mesial ICF is CO broad. The specimen shows hypoplasias, as well as a few antemortem use-scratches. Maximum crown thickness at the naturally broken paracone is $\sim 2.2 \mathrm{~mm}$.

Member 2/Member 3 interface fossils

SWT2/3-1 (Figure 5a; Table 3): This well-preserved crown of a right permanent mandibular first molar $\left(\mathrm{RM}_{1}\right)$ was probably unerupted at the time of death; the occlusal surface is unworn and the mesial and distal faces lack ICFs. The crown terminates in ancient fractures just inferior to CEJ so it is not possible to determine definitively the state of root formation at the time of the individual's demise. The moderately crenullated crown is five-cusped, arranged in a Y-5 main occlusal pattern (with the mesiobuccal groove situated mesial to the lingual groove) within an ovorectangular outline. The region of the anterior fovea is shallow, is elaborated with accessory wrinkles and is not clearly delineated from the central fossa. The distal marginal ridge of the crown is incised by fissures but does not support a clearly developed tuberculum sextum. The buccal face of the crown slopes acutely lingually, while the lingual face slopes only slightly buccally. Cusp heights are: metaconid $=7.2 \mathrm{~mm}$ (estimated); protoconid $=9.7 \mathrm{~mm}$; hypoconid $=9.1 \mathrm{~mm} ;$ entoconid $=7.5 \mathrm{~mm}$ (estimated); hypoconulid $=8.3 \mathrm{~mm}$. A single lingual furrow is apparent but is much less wellexpressed than are the mesial and distal buccal furrows, both of which are deep and terminate cervically in foramen caeca. Furrow lengths (from occlusal margin cervically) are: lingual =1.0 mm; mesiobuccal $=4.4 \mathrm{~mm}$; distobuccal $=3.0 \mathrm{~mm}$.

SWT2/3-2 (Figure 3a; Table 3): The roots of this $\mathrm{Rdm}^{2}$ are resorbed, but its four-cusped crown is complete and well-preserved. The squarish occlusal outline of SWT2/3-2 is uncommon for a $P$. robustus deciduous maxillary molar and is more similar to that of early Homo $\mathrm{M}^{1} \mathrm{~s}$. However, the 
MD (9.9 mm) and BL (11.5 mm) diameters of SWT2/3-2 fall outside the published ranges for MD and BL diameters of South African early Homo M1s (MD range = $12.7-13.9 \mathrm{~mm}$, mean = 13.2, $n=9$; BL range $=12.2-13.4 \mathrm{~mm}$, mean $=13.0 \mathrm{~mm}, n=8)($ Moggi-Cecchi et al., 2010) and are closer to the low ends of the ranges for MD and BL diameters of $P$. robustus $\mathrm{dm}^{2} \mathrm{~s}$ from Swartkrans and Drimolen (Table 3).

In addition, the crown of SWT2/3-2 lacks any indication of a Carabelli's trait mesiolingually and its buccal groove terminates in a pit-features more typical of P. robustus than of early Homo (Grine, 1984, 1989). The crown also shows two major regions of dentine exposure. The first is a deeply invasive, areally expansive, crescent-shaped basin that connects the obliterated paracone, protocone and hypocone; the second is a Reuleaux triangular-shaped pit centered near the apex of the metacone and of roughly the same depth as the other occurrence. This near-coplanar pattern of occlusal wear-including, especially, the basin of dentine that expands uninterrupted across the mesial and distolingual cusps of SWT2/3-2-is typical of P. robustus (Grine, 1981); indeed, the wear pattern of SWT2/3-2 is similar (but even more advanced) to that of SKX 32832, a previously described P. robustus $\mathrm{dm}^{2}$ from Swartkrans (Grine, 1993). The marginal ridge of SWT2/3-2 is still fairly prominent distally and lingually, but is rounded over at the junction of the crown's occlusal surface and its buccal face and is completely worn through mesially, where a BL-wide $(6.3 \mathrm{~mm})$ and CO-short $(\sim 1.0 \mathrm{~mm})$ ICF descends the crown's face to meet its occlusal surface at the mesial edge of the crown. The distal ICF is ovorectangluar in shape $(\mathrm{BL}=5.7 \mathrm{~mm} ; \mathrm{CO}=3.1 \mathrm{~mm})$. The fact that mesial ICF of SWT2/3-2 is BL broader than its distal ICF provides additional support for identification of the tooth as a P. robustus $\mathrm{dm}^{2}$. If SWT2/3-2 was, instead, an $\mathrm{M}^{1}$ of early Homo, we expect that its mesial ICF would be less prominent, as that ICF of this very worn tooth would have been in contact with the distal ICF of a $\mathrm{P}^{4}$; compared to the $\mathrm{dm}^{1}$, the $\mathrm{P}^{4}$ erupts later and provides a less significant surface against which the $\mathrm{M}^{1}$ abuts. 


\section{Member 3 fossils}

SWT3-1 (Figure 2e; Table 3): This $\mathrm{LI}^{2}$ is essentially complete, missing just the apex of its root. The preserved portion of the root measures $13.4 \mathrm{~mm}$ labially and $14.3 \mathrm{~mm}$ lingually in length from the CEJ to its superior termination. The root is MD thick (maximum MD root width $=5.9 \mathrm{~mm}$ ) from the CEJ superiorly nearly to its superior termination. The root deflects very slightly in a distal direction superiorly. The enamel cap is completely worn through at the incisal plane, which now presents as a flat-tabled, highly polished, unbroken surface of exposed dentine that tips appreciably distolingually. The maximum height of the crown's labial face $(6.3 \mathrm{~mm})$ is found at its mesial corner. Set distal to this maximum height, the incisal edge of the labial face displays a prominent antemortem chip that has been smoothed over and polished through subsequent use of the tooth by the SWT3-1 individual. The labial face of the crown also shows numerous antemortem scratches and minor developmental pitting. Except for tiny hinges of enamel that overlap from the corners of the labial face onto the mesial and distal surfaces of the inferior root, the enamel rim is obliterated on the mesial and distal faces of the tooth. A minuscule ICF ( $L L=1.3 \mathrm{~mm} ; \mathrm{CO}=1.4 \mathrm{~mm}$ ) is apparent on the hinge of enamel that wraps onto the mesial face and a similarly diminutive indentation (in the rough form of a circular segment) marks the presumed location of the distal ICF set into the inferior root surface, just distal to the enamel hinge on that side of the tooth. The lingual face of the crown is evinced by a short flange of remaining enamel (maximum CO height $=2.1 \mathrm{~mm}$; maximum MD breadth $=3.4 \mathrm{~mm}$ ).

SWT3-2 (Figure 5b; Table 3): This large, glossily manganese dioxide-stained, right permanent mandibular second molar $\left(\mathrm{LM}_{2}\right)$ is generally well-preserved but is missing two chips of enamel: the first ( $~ 7.5 \mathrm{~mm} \mathrm{MD} \mathrm{x} \sim 2.0 \mathrm{~mm}$ CO) spans the mesiobuccal corner of the crown face, obliterating the 


\section{Pickering et al.}

$\mathrm{CEJ}$ in that region; the second ( $\sim 4.6 \mathrm{~mm} \mathrm{MD)} \mathrm{extends} \mathrm{cervically} \mathrm{from} \mathrm{the} \mathrm{lingual} \mathrm{corner} \mathrm{of} \mathrm{the}$ metaconid onto the lingual face of the crown, continuing inferiorly and having removed the lingual face of the crown-ward extension of the mesial root. The rest of the mesial root is also missing, removed by a separate chip. All three damaged areas were fractured in the postmortem interval but are also ancient, as evidenced by the fact that breccia adhered to their surfaces. The fully fused distal root is largely intact, with minor ancient chipping and erosion of its lingual apex in particular. The distal root is grooved and its maximum length (from CEJ to buccal apex) is $16.72 \mathrm{~mm}$. There is a slightly chipped but well-developed radix endomolaris partially fused to the distal root and inferior to the entoconid. The occlusal outline of the crown is ovorectangular and includes a small hypoconulid, as well as a small triangular tuberculum sextum and a BL elongated tuberculum intermedium. Although the occlusal surface still evinces its fissure pattern (filled with breccia), it is worn flat, with three semi-circular exposures of dentine, one on the protoconid, one on the hypoconid and one on the hypoconulid. There are fine, BL-trending antemortem scratches on the crown, interspersed with occasional, larger striations and developmental pitting. Enamel thickness at the metaconid is $\sim 1.6 \mathrm{~mm}$. Both ICFs are relatively large and well-developed (mesial ICF maxima, $6.2 \mathrm{~mm}$ BL x $2.9 \mathrm{~mm}$ CO; distal ICF maxima, $6.9 \mathrm{~mm}$ BL x $4.2 \mathrm{~mm}$ CO). The distal ICF is secondarily modified with a BL elongated pit at its occlusolingual margin, where the enamel was chipped antemortemly and then polished smooth as the SWT3-2 individual continued to use its teeth.

SWT3-2433 (Figure 2b; Table 3): Overall, this well-preserved Ldi1 ${ }^{1}$ is less worn but otherwise reminiscent of SWT1/LB-19, described above. The root of SWT3-2433 is partially resorbed. From the CEJ to its superior termination, the root measures $8.7 \mathrm{~mm}$ in length labially and $9.0 \mathrm{~mm}$ lingually. The root is broad MD (maximum MD width $=6.1 \mathrm{~mm}$ ) relative to its flatness $\mathrm{LL}$ (maximum LL breadth $=3.2 \mathrm{~mm}$ ). The margin of the incisal plane is nearly unworn and bevels cervico-lingually. The mesial and distal corners of the crown's incisal margin are sharp, as is its 
Pickering et al.

labial edge, which angles markedly in a cervico-distal direction. The crown bulges dramatically around the entire circumference of the enamel line but especially labially, mesially and distally, conveying a distinctly constricted appearance to the CEJ in labial and lingual views. Together, the angle of the crown's labio-incisal edge and its dramatic sub-CEJ mesial bulge convey to it an exaggerated "distal reduced" labial outline (Hillson, 1996). The lingual cervical prominence of the crown is modest and skews distally; there is no lingual shoveling. Maximum crown height labially is $6.6 \mathrm{~mm}$. The mesial ICF is a deep, well-developed crescent that spans the incisal margin to the incisal third of the mesial crown face. There is a series of antemortem microchips along the labial incisal margin; the labial face of the crown is scarred by a large scratch and several smaller ones, as well as wear-pits; developmental pits occur across the crown.

\section{“Underground North Excavation” fossil}

SWT/UNE-1 (Figure 2f; Table 3): The root (labial height from CEJ to tip $=9.7 \mathrm{~mm}$; lingual height from CEJ to tip $=9.4 \mathrm{~mm}$ ) of this well-preserved $\mathrm{RC}^{1}$ is incompletely formed and its open superior termination is partially filled with red, lightly calcified sediment. The crown is unworn (labial height $=13.8 \mathrm{~mm}$ ) and lacks ICFs, but does show developmental pitting of the enamel. The mesial shoulder of the apical margin is more steeply sloping than is the distal apical edge; these edges converge in a pointed apex that is slightly offset distally from the midcrown transverse axis, imparting to the crown a pentagonid outline in labial view. The cervical line is more curved mesially than it is distally. The lingual cervical eminence is modestly developed; the mesial and distal marginal ridges are clearly separated by well-defined furrows from the more slightly constructed medial ridge, which flattens towards the cuspal apex.

\section{Taxonomic attributions}


Pickering et al.

Permanent maxillary lateral incisors Because the two new I²s, SWT1/LB-18 and SWT3-1, are essentially complete, we have a fair degree of confidence in assigning both to P. robustus. Quantitative comparisons were, however, of limited use in arriving at these attributions. For instance, Figure 6a demonstrates graphically the remarkable intertaxonomic variability in BL:MD ratios among our comparative sample of fossil hominin I²s, confirming Robinson's (1956: 216) early observation that the maxillary incisors of various Pleistocene taxa agree largely in "size and structure." The relative ineffectiveness of a metric approach to taxonomic assignment in the cases of SWT1/LB-18 and SWT3-1 is compounded by the fact that both fossils are appreciably incisally worn, the latter especially so.

The qualitative characteristics of SWT/LB-18 and SWT3-1 justify their attributions to P. robustus much better than do metric data. As is typical for Paranthropus, and atypical for other relevant taxa, both specimens possess roots that are markedly LL expanded near their midpoints and that taper rather affectedly toward their apices (Robinson, 1956). The gingival eminence of SWT3-1 is obliterated by incisal wear. However, the same feature is preserved on SWT1/LB-18 - and although it is symmetrically placed and protrudes relatively prominently, it is not in any way hypertrophic or unusually elaborated with subdivisions or other accessories; in contradistinction to normal variation observed in many other hominin taxa, the maxillary incisors of $P$. robustus do not typically possess exaggerated or partitioned lingual tubercles (Robinson, 1956; Grine, 1989). In addition, it is only because of significant incisal wear that the crown of SWT1/LB-18 shows a slightly spatulate labial outline; the crown's projected unworn outline is more ovoid, as is typical for $P$. robustus $I^{2}$ s (Grine, 1989). Plus, in being slightly convex, the labial face of the crown is more like those of Paranthropus incisors, and less like the flatter labial crown faces of Australopithecus and Homo incisors. Last, the incisal surfaces of SWT1/LB-18 and SWT-3 are both worn flat through their enamel caps, the former assuming a near-perpendicular orientation relative to the long axis of 


\section{Pickering et al.}

the crown, the latter, a distolingual bevel-wear patterns characteristic of P. robustus maxillary incisors (Ungar and Grine, 1991).

Permanent maxillary canines The two new $\mathrm{C}^{1} \mathrm{~s}$ are differentially preserved: SWT1/LB-17 is essentially the lingual face of a crown attached to a root stump, while SWT/UNE-1 is one of the most complete, beautifully preserved specimens in the entire hominin tooth sample from Swartkrans. Because of its incompleteness, the former specimen is not assignable beyond the level Hominidae gen. et sp. indet. In contrast, the latter is complete enough for it to be assigned to $P$. robustus with a good degree of certainty.

The completely unworn MD (7.8 mm) and BL (9.2 mm) diameters of SWT/UNE-1 match more closely the standard occlusal dimensions of P. robustus $\mathrm{C}^{1} \mathrm{~s}$ (Table 3; Figure $6 \mathrm{~b}$ ), than they do of early Homo, including South African early Homo (MD mean = $10.0 \mathrm{~mm}$, range = 9.3 - $10.7 \mathrm{~mm}, n=3$; $\mathrm{BL}$ mean $=9.5 \mathrm{~mm}$, range $=8.8-10.3 \mathrm{~mm}, n=3$ ) (Moggi-Cecchi et al., 2010). Qualitatively, SWT/UNE-1 deviates from typical $P$. robustus $\mathrm{C}^{1}$ morphology in possessing a CEJ that lacks significant bulging along its entire circumference. However, the tooth does follow a P. robustus C1pattern in showing lingually a central buttress and especially a cingulum bulge of the tuberculum that are more weakly developed than are its moderately developed marginal ridges. In addition, as is typical for the $\mathrm{C}^{1} \mathrm{~s}$ of P. robustus and less so for those of early Homo and other hominin taxa, the lingual grooves of SWT/UNE-1 converge strongly toward the gingival eminence (Robinson, 1956).

Permanent maxillary molars The two new permanent maxillary molars, SWT/TC-5 and SWT/TC-8, are from the TCD; although the latter has suffered some damage, both are excellently preserved and suitable for taxonomic analyses. SWT/TC-8 is an enormous tooth, with the largest MD diameter of any known South African hominin M11; indeed, based on BL: MD ratio, it groups most closely with 


\section{Pickering et al.}

some of the largest known $\mathrm{M}^{1} \mathrm{~s}$ of East African P. boisei (Figure 6c). Displaying the following features, SWT/TC-8 is, on a morphological basis, placed comfortably into the genus Paranthropus (Robinson, 1956; Wood and Engleman, 1983; Grine, 1989): it possesses thick enamel (measured at its naturally broken paracone, as reported above), its cusps are low and rounded, its cusp ridges slope centrally, its Carabelli's effect is typical of P. robustus (assuming the form of a pit), and its buccal groove is short, terminating low on the buccal crown face.

Based on morphology, the new M² SWT/TC-5 is, like SWT/TC-8, clearly derived from a Paranthropus individual: all of its unworn cusp tips are low, rounded and converge centrally, and its buccal groove is short, terminating low on the buccal crown face (Robinson, 1956; Wood and Engleman, 1983; Grine, 1989). In addition, "[w]hile the taxonomic assessment of any fossil should be morphologically driven, contextual information is not wholly irrelevant" (Grine et al., 2012: 599). To wit, the description of SWT/TC-5 (above) provides taphonomic context suggesting strongly that it derived from the same individual as the previously described P. robustus $\mathrm{M}^{1}$, SWT/TC-2 (Sutton et al., 2009). Last, Figure 6d shows that, based BL: MD ratio, SWT/TC-5 groups comfortably with the $\mathrm{M}^{2} \mathrm{~s}$ of $P$. robustus.

Permanent mandibular molars The two new permanent mandibular molars, SWT2/3-1 and SWT32, are well-preserved and thus both are also confidently assigned to P. robustus. Based on BL: MD ratio, SWT2/3-1 is fairly small for a P. robustus $\mathrm{M}_{1}$, but still falls at the low end of the range for that species (Figure 6e). Despite its small size, SWT2/3-1, with its convex-sided crown and low, inflated cusps, conforms morphologically to typical P. robustus $\mathrm{M}_{1} \mathrm{~S}$ (Robinson, 1956; Wood and Abbott, 1983; Wood et al., 1983; Grine, 1989; Suwa et al., 1994, 1996): it is ovorectangular in occlusal 
Pickering et al.

outline; the buccal face of the crown slopes more sharply lingualward than does the lingual face buccalward, it lacks a well-developed protoconidal cingulum, its anterior fovea is not distinctly separated from its central fossa, and the buccal furrows terminate cervically in foramen caeca.

In contrast to the rather diminutive SWT2/3-1, SWT3-2 is one of the largest known $M_{2} \mathrm{~S}$ in the South African hominin fossil record (Figure 6f). Thus, based on size alone, SWT3-2 aligns unambiguously with the genus Paranthropus (e.g., Wood and Abbott, 1983; Suwa et al., 1994, 1996). In addition, the specimen also displays several taxonomically salient morphological traits (Robinson, 1956; Wood and Abbott, 1983; Wood et al., 1983; Grine, 1989; Suwa et al., 1994, 1996) that confirm that placement: it possesses both a tuberculum sextum and a tuberculum intermedium; despite the fact that its occlusal surface is well worn into a flat table, the specimen still maintains appreciable crown height and its dentinal exposure is minimal, which, taken together, evince substantial enamel thickness; judging from the relatively smooth circumferential contact between the tooth's occlusal margin and its crown face, its unworn cusps would have been low and bulbous.

Deciduous maxillary central incisors There are two well-preserved di ${ }^{1}$ s, SWT1/LB-19 and SWT32433, in the new Swartkrans dental sample. Unfortunately, there are very few other $\operatorname{di}^{1} \mathrm{~s}$ in the relevant hominin fossil record to which these newly discovered teeth can be compared (Figure 6g). SWT1/LB-19 is considerably incisally worn, while SWT3-2433 is only lightly worn, but otherwise the two teeth are remarkably similar. The roots of both are partially resorbed and are both MD broad and LL flat; the crowns of both bulge noticeably—especially mesially-inferior to their CEJs; in overall root and crown form both new teeth are thus grossly similar to SKX 16060, an $\operatorname{Rdi}^{1}$ of $P$. robustus described by Grine (1993). More, in a macrowear pattern characteristic of $P$. robustus 
Pickering et al.

permanent maxillary incisors (Ungar and Grine, 1991), as well as that of SKX 16060, SWT1/LB-19 is beveled distolingually. For these qualitative reasons, we assign both new $\operatorname{di}^{1} \mathrm{~s}$ to $P$. robustus.

Deciduous maxillary second molars_Figure 6h summarizes a comparison of the BL: MD ratio of SWT2/3-2 to those of other relevant hominin $\mathrm{dm}^{2} \mathrm{~s}$. It is obvious that SWT2/3-2 is smaller than is expected for a P. robustus $\mathrm{dm}^{2}$. However, because taxonomic diagnosis of the tooth was integral to its identification as a $\mathrm{dm}^{2}$, we have already enumerated in its description (above), the qualitative characters of the SWT2/3-2 that ally it with P. robustus. We also noted the striking similarity between SWT2/3-2 and SKX 32832, a previously described P. robustus $\mathrm{dm}^{2}$ from Swartkrans (Grine, 1993). SWT1/LB-20, the other new $\mathrm{dm}^{2}$, is heavily worn (and is unsuitable for metric comparisons), but it conforms geometrically and morphologically to SWT2/3-2 (Figure 3) (and to SKX 32832; Grine, 1993) and, thus, is also placed in P. robustus.

\section{Discussion}

All but three of the 14 newly reported hominin fossils from Swartkrans are assignable to the species level (Table 2). The 11 specifically assignable teeth conform morphologically to the previously described P. robustus hypodigm (e.g., Broom and Robinson, 1952; Grine, 1989, 1993; Keyser et al., 2000; Moggi-Cecchi et al., 2010; Pickering et al., 2012) and, because so, are placed in that taxon.

Included in the new sample of P. robustus teeth is SWT/TC-5, a P. robustus $\mathrm{LM}^{2}$, which joins SWT/TC-2 (Sutton et al., 2009) as among the smallest maxillary molars ever recovered from Swartkrans (Table 3). Both specimens were excavated from the TCD, a recently recognized 


\section{Pickering et al.}

geological unit that is not yet dated absolutely but that postdates the deposition of the LB of Member 1 (average cosmogenic nuclide burial dating age $=1.99 \pm 0.19 \mathrm{Ma}$ ) and predates $\sim 108,000$ years old (Sutton et al., 2009). Given (1) the TCD's post-LB stratigraphic position and (2) the secure, in situ context of SWT/TC-2 and SWT/TC-5, there remains no good evidence of an intrasite diachronic trend in P. robustus postcanine tooth size at Swartkrans: P. robustus maxillary first and second molars from the LB are larger than are SWT/TC-2 and SWT/TC-5, both from the more recent TCD; in addition, SWT3-2, a new specimen described here and one of the geologically youngest P. robustus $\mathrm{M}_{2} \mathrm{~S}$ (Member 3, $0.96 \pm 0.09 \mathrm{Ma}$ ) from Swartkrans, is also one of the largest (Table 3). Similarly, based on his analysis of a very large collection of hominin teeth from Swartkrans, Grine (1993: 106) concluded the MD and BL diameters of "several of the teeth from Members 2 and 3 [more recent] fall slightly beyond the observed ranges for the Member 1 Hanging Remnant sample [older], but in most instances the latter sample consists of comparatively few specimens." More, because of its currently understood age of 2.0 - 1.5 Ma (Keyser et al., 2000)—a broad range, which overlaps temporally with much of the early Pleistocene portion of the Swartkrans Formation - the relatively small-toothed and morphologically demonstrated $P$. robustus sample from Drimolen currently sheds no light on the possibility of dental size polarity in this species.

These findings tend to support Keyser et al.'s (2000; see also, Moggi-Cecchi et al., 2010) falsification of the hypothesis that South African Paranthropus is composed of more than one species, $P$. robustus and P. crassidens (e.g., Broom, 1949; Howell, 1978; Grine, 1982, 1984, 1985, 1993; Jungers and Grine, 1986). Instead, analyses of new fossils seem to confirm the presence of a single, moderately morphologically variable endemic species of Paranthropus, P. robustus, over time and across geography in South Africa. Of course, future discoveries hold the potential to change this 


\section{Pickering et al.}

view, but considering the exceptional range of body size inferred for South African Paranthropus, its probable monospecificity is all the more remarkable.

It is largely "because of temporal (and probably taxonomic) differences in relative tooth size among hominins" (Ruff, 2002: 213) that the few attempts to predict extinct hominin body mass from tooth dimensions are viewed so dubiously. In contrast, more convincing estimates of hominin body size are based on cranial and postcranial data (e.g., McHenry, 1976; 1988, 1991, 1992; Steudel, 1980; Jungers, 1988; Aiello and Wood, 1994; Kappleman, 1996; Lockwood et al., 2007; Spocter and Manger, 2007; Kaszycka, 2016), with multiple studies concluding that P. robustus was characterized by significant body size sexual dimorphism (BSSD), which perhaps approached or even exceeded that of extant gorillas (Gorilla spp.). Following from this supposition, it is logical that the largest permanent postcanine teeth in the P. robustus hypodigm are usually diagnosed as those of males and the smallest, those of females (e.g., Grine et al., 2012). The extreme degree of BSSD inferred for P. robustus holds significant biological implications for reconstructing the mating and social systems of that extinct species (see, e.g., Calder, 1984; Leigh, 1995; Plavcan, 2000, 2012).

It has been suggested further that size disparity in P. robustus fossils also holds similarly significant implications for reconstructing the formation histories of their bone assemblages. Generally speaking, various studies agree that many (if not most) of the macromammalian assemblages from the Swartkrans Formation formed, in large part, through the predatory, carcass consumption and depositional activities of large carnivores (e.g., Brain, 1970, 1981, 1993a; Pickering, 2001; Pickering and Carlson, 2002; Carlson and Pickering, 2003; Pickering et al., 2004, 2008). This hypothesis predicts, in turn, that resultant faunas should be dominated by the remains of small (presumably prey) animals (e.g., Brain, 1981; Susman et al., 2001; Pickering et al., 2004, 2008; Grine et al., 2012). The purported predominance of remains from small P. robustus individuals (presumptive females 


\section{Pickering et al.}

and/or subadults of both sexes), and the corresponding rarity of remains from larger individuals (presumptive old adult males) at Swartkrans meets this prediction and suggests to some that $P$. robustus sub-assemblages (like those of other macromammalian taxa) may have formed under conditions of taphonomically based size-sorting (e.g., Susman et al., 2001; Lockwood, 2007; Grine et al., 2012).

Concerning the new sample of teeth described above, the small sizes of SWT/TC-2 and SWT/TC-5 are certainly consistent with the hypothesis that the individual(s) from which they derived was/were deposited at Swartkrans by a predator(s) (cf. Brain, 1981; Grine et al., 2012). However, SWT/TC-8, a newly identified P. robustus $\mathrm{M}^{1}$ from the same TCD unit as the diminutive SWT/TC-2 and SWT/TC-5 specimens, appears to be the largest (because of pre-recovery damage, its MD and BL diameters are necessarily conservative estimates) P. robustus $\mathrm{M}^{1}$ in the entire fossil record (Table 3; Figure 8). This is not to suggest that the predator-collecting hypothesis for Swartkrans is necessarily falsified; instead, only that caution is warranted.

Against a similarly cautious attitude adopted by Moggi-Cecchi et al. (2010), predator-collecting hypotheses of $P$. robustus assemblage formation are often assumed or even postulated for nearby and penecontemporaneous Drimolen (e.g., Grine et al., 2012)—a site that is also characterized by a preponderance of fossils that derived from small P. robustus individuals. However, recent analysis of intersite P. robustus mortality patterns (Mori et al., 2013) suggests that the Drimolen fossils-a sample comprising, in part, remains of ontogenetically younger individuals than at Swartkransaccumulated under different conditions and by different mechanisms (e.g., including probably nonpredation related mortality of infants and juveniles) compared to those that operated to form the Swartkrans assemblage. In sum, we reiterate our earlier conclusion (Pickering et al., 2012) that, for lack of supporting data, it is still premature to conclude that hominin assemblages from various 
Pickering et al.

South African caves all formed solely or even largely under conditions of taphonomically based size-sorting.

\section{Conclusion}

The fossils described here add to the important evolutionary record of early Pleistocene hominins that is preserved in the sedimentary sequence of Swartkrans Cave. Specifically, the new sample bolsters the status of Swartkrans as the single most generous repository of P. robustus fossils anywhere in the world. In addition, our results document the expanded areal and stratigraphic ranges of Pleistocene fossil-bearing deposits at Swartkrans and thus indicate our future directions for research at the site.

\section{Acknowledgments}

The Swartkrans Paleoanthropology Research Project (SPRP) is supported by grants to: T.R. Pickering from the National Science Foundation (USA), the L.S.B. Leakey Foundation, the Palaeontological Scientific Trust (PAST, South Africa), and the Vilas Associates and Kellet MidCareer Award Programs (University of Wisconsin-Madison); M. Sutton from the University of the Witwatersrand, the National Research Foundation (NRF, South Africa) and PAST; and K. Kuman from the NRF African Origins Platform and PAST. We thank the following individuals, institutions, and companies (in alphabetical order) for their assistance with our project: African Explosives; the Brain/Newman/Watson family; Laurent Bruxelles; John Cruise; Hendrick Dingiswayo; the Ditsong National Museum of Natural History (Transvaal Museum); Manuel Domínguez-Rodrigo; Sarah 
Pickering et al.

Edlund; Charles Egeland; the Evolutionary Studies Institute, University of the Witwatersrand; Ryan Gibbon; Andi Heile; Barry Jacoby; Lazarus Kgasi; Andrea Leenen; Isaac Makhele; Abel Molepolle; Andrew Phaswana; the Pickering family (especially Robert for his fieldwork); Stephany Potze; the late Dusty van Rooyen; the School of Geography, Archaeology and Environmental Studies, University of the Witwatersrand; Lucas Sekowe; Solomon Seshoene; Dominic Stratford; Francis Thackeray. Thanks to an anonymous Associate Editor and three anonymous reviewers who provided very useful comments that improved this paper. Very special thanks to Jacopo MoggiCecchi for sharing data and advice and to Sarah Elton for her expert handling of this paper. This is paper No. 6 in the SPRP publication series.

\section{References}

Aiello, L.C., Wood, B.A., 1994. Cranial variables as predictors of hominid body mass. Am. J. Phys. Anthropol. 95, 409-426.

Backwell, L.R., d'Errico, F., 2003. Additional evidence on the early hominid bone tools from Swartkrans with reference to spatial distribution of lithic and organic artifacts. S. Afr. J. Sci. 99, 259267.

Brain, C.K., 1958. The Transvaal Ape-Man-Bearing Deposits. Transvaal Museum, Pretoria. 
Pickering et al.

Brain, C.K., 1970. New finds at the Swartkrans australopithecine site. Nature 225, 1112-1119.

Brain, C.K., 1976. A re-interpretation of the Swartkrans site and its remains. S. Afr. J. Sci. 72, 141146.

Brain, C.K., 1981. The Hunters or the Hunted? An Introduction to African Cave Taphonomy. University of Chicago Press, Chicago.

Brain, C.K. (Ed.), 1993a. Swartkrans: a Cave’s Chronicle of Early Man. Transvaal Museum, Pretoria.

Brain, C.K., 1993b. Structure and stratigraphy of the Swartkrans cave in the light of the new excavations. In: Brain, C.K. (Ed.), Swartkrans: A Cave’s Chronicle of Early Man. Transvaal Museum, Pretoria, pp. 23-33.

Brain, C.K., Robinson, J.T., 1953. A geological note on the australopithecine-bearing deposit at Swartkrans. Congrès Geologique International, Sec. V, Alger 1952: 55-56.

Brain, C.K., Churcher, C.S., Clark, J.D., Grine, F.E., Shipman, P., Susman, R.L., Turner, A., Watson, V., 1988. New evidence of early hominids, their culture and environment from the Swartkrans Cave, South Africa. S. Afr. J. Sci. 84, 828-835.

Broom, R. 1938. Pleistocene anthropoid apes of South Africa. Nature 142, 377-379.

Broom, R., 1949. Another new type of ape-man. Nature 163, 57. 
Pickering et al.

Broom, R., Robinson, J.T., 1949. A new type of fossil man. Nature 164, 322.

Broom, R., Robinson, J.T., 1950. Man contemporaneous with the Swartkrans apeman. Am. J. Phys. Anthropol. 8, 151-156.

Broom, R., Robinson, J.T., 1952. Swartkrans Ape-Man Paranthropus crassidens. Transvaal Museum, Pretoria.

Butzer, K., 1976. Lithostratigraphy of the Swartkrans Formation. S. Afr. J. Sci. 72, 136-141.

Calder, W.A., 1984. Size, Function and Life History. Harvard University Press, Cambridge.

Carlson, K.J., Pickering, T.R., 2003. Intrinsic qualities of primate bones as predictors of skeletal element representation in modern and fossil carnivore feeding assemblages. J. Hum. Evol. 44, 431450.

Churcher, C.S., Watson, V., 1993. Additional fossil Equidae from Swartkrans. In: Brain, C.K. (Ed.), Swartkrans: A Cave's Chronicle of Early Man. Transvaal Museum, Pretoria, pp. 137-150.

Clarke, R.J., 1977. The cranium of the Swartkrans hominid, SK 847, and its relevance to human origins. Ph.D. Dissertation, University of the Witwatersrand, Johannesburg.

Clarke, R.J., 2008. Latest information on Sterkfontein's Australopithecus skeleton and a new look at Australopithecus. S. Afr. J. Sci. 104, 443-449. 


\section{Pickering et al.}

Clarke, R.J., 2012. A Homo habilis maxilla and other newly discovered hominid fossils from Olduvai Gorge, Tanzania. J. Hum. Evol. 63, 418-428.

Clarke, R.J., 2013. Australopithecus from Sterkfontein Caves, South Africa. In: Reed, K., Fleagle, J., Leakey, R.E.F. (Eds.), Paleobiology of Australopithecus. Springer, New York, pp. 105-123.

Clarke, R.J., Howell, F.C., 1972. Affinities of the Swartkrans 847 cranium. Am. J. Phys. Anthropol. 37, $319-336$.

Clarke, R.J., Howell, F.C., Brain, C.K., 1970. More evidence of an advanced hominid at Swartkrans. Nature 225, 1219-1222.

Gibbon, R.J., Pickering, T.R., Sutton, M.B., Heaton, J.L., Kuman, K., Clarke, R.J., Brain, C.K., Granger, D.E., 2014. Cosmogenic nuclide burial dating of hominin-bearing Pleistocene cave deposits at Swartkrans, South Africa. Quat. Geochron. 24, 10-15.

Grine, F.E., 1981. Trophic differences between "gracile" and "robust" australopithecines: a scanning electron microscope analysis of occlusal events. S. Afr. J. Sci. 77, 203-230.

Grine, F.E., 1982. A new juvenile hominid (Mammalia: Primates) from Member 3, Kromdraai Formation, Transvaal, South Africa. Ann. Transv. Mus. 33, 165-239.

Grine, F.E., 1984. The deciduous dentition of the Kalahari San, the South African Negro and the South African Plio-Pleistocene hominids. Ph.D. Dissertation, University of the Witwatersrand, Johannesburg. 
Pickering et al.

Grine, F.E., 1985. Australopithecine evolution: the deciduous dental evidence. In: Delson, E. (Ed.), Ancestors: The Hard Evidence. Alan R. Liss, New York, pp. 153-167.

Grine, F.E. 1988. Analysis of new craniodental specimens of Paranthropus from the Swartkrans Formation. In: Grine, F.E. (Ed.) Evolutionary History of the "Robust” Australopithecines. Aldine de Gruyter: New York, pp. 223-245.

Grine, F.E., 1989. New hominid fossils from the Swartkrans Formation (1979 - 1986 excavations): craniodental specimens. Am. J. Phys. Anthropol. 79, 409-449.

Grine, F.E., 1993. Description and preliminary analysis of new hominid craniodental fossils from the Swartkrans Formation. In: Brain, C.K. (Ed.), Swartkrans: A Cave’s Chronicle of Early Man. Transvaal Museum, Pretoria, pp. 76-116.

Grine, F.E., 2005. Early Homo at Swartkrans, South Africa: a review of the evidence and an evaluation of recently proposed morphs. S. Afr. J. Sci. 101, 43-52.

Grine, F.E., Jacobs, R.L., Reed, K.E., Plavcan, J.M., 2012. The enigmatic molar from Gondolin, South Africa: implications for Paranthropus paleobiology. J. Hum. Evol. 63, 597-609.

Hillson, S., 1996. Dental Anthropology. Cambridge University Press, Cambridge.

Howell, F.C., 1978. Hominidae. In: Maglio, J.V., Cooke, H.B.S. (Eds.), Evolution of African Mammals. Harvard University Press, Cambridge, pp. 154-248. 


\section{Pickering et al.}

Jungers, W.L., 1988. New estimates of body size in australopithecines. In: Grine, F.E. (Ed.),

Evolutionary History of the "Robust" Australopithecines. Aldine de Gruyter, New York, pp. 115-125.

Jungers, W.L., Grine F.E., 1986. Dental trends in the australopithecines: the allometry of mandibular molar dimensions. In: Wood, B.A., Martin, L.B., Andrews, P. (Eds.), Major Topics in Primate and Human Evolution. Cambridge University Press, Cambridge, pp. 203-219.

Kappelman, J., 1996. The evolution of body mass and relative brain size in fossil hominids. J. Hum.

Evol. 30, 243-276.

Kaszycka, K.A., 2016. Australopithecus robustus societies-one-male or multimale? S. Afr. J. Sci. 112, 124-131.

Keyser, A.W., Menter, C.G., Moggi-Cecchi, J., Pickering, T.R., Berger, L.R., 2000. Drimolen: a new hominid-bearing site in Gauteng, South Africa. S. Afr. J. Sci. 96, 193-197.

Leakey, R.E.F., 1973. Evidence for an advanced Plio-Pleistocene hominid from East Rudolf, Kenya. Nature 242, 447-450.

Leigh, S.R., 1995. Socioecology and the ontogeny of sexual size dimorphism in anthropoid primates. Am. J. Phys. Anthropol. 97, 339-356.

Lockwood, C.A., Menter, C.G., Moggi-Cecchi, J., Keyser, A., 2007. Extended male growth in a fossil hominin species. Science 318, 1443-1446. 
Pickering et al.

McHenry, H.M., 1976. Early hominid body weight and encephalization. Am. J. Phys. Anthropol. 45, 77-84.

McHenry, H.M., 1988. New estimates of body weight in early hominids and their significance to encephalisation and megadontia in "robust" australopithecines. In: Grine, F.E. (Ed.), Evolutionary History of the "Robust" Australopithecines. Aldine de Gruyter, New York, pp. 133-148.

McHenry, H.M., 1991. Petite bodies of the "robust" australopithecines. Am. J. Phys.

Anthropol. 86, 445-454.

McHenry, H.M., 1992. Body size and proportions in early hominids. Am. J. Phys. Anthropol. 87, 407431.

Menter, C.G., Kuykendall, K.L., Keyser, A.W., Conroy, G.C., 1999. First record of hominid teeth from the Plio-Pleistocene site of Gondolin, South Africa. J. Hum. Evol. 37, 299-307.

Moggi-Cecchi, J., Grine, F.E., Tobias, P.V., 2006. Early hominid dental remains from Members 4 and 5 of the Sterkfontein Formation (1966 - 1996 excavations): catalogue, individual associations, morphological descriptions and initial metrical analysis. J. Hum. Evol. 50, 239-328.

Moggi-Cecchi, J., Menter, C., Boccone, S., Keyser, A., 2010. Early hominid dental remains from the Plio-Pleistocene site of Drimolen, South Africa. J. Hum. Evol. 58, 374-405. 
Pickering et al.

Mori, T., Moggi-Cecchi, J., Pickering, T.R., Menter, C.G., 2013. Distribution of ages-at-death of fossil hominins from the early Pleistocene site of Drimolen, South Africa: preliminary results and behavioral implications. Abstracts for the Third Annual Meeting of European Society for the Study of Human Evolution, held in Vienna, Austria, p. 158.

Palmer, A.N., 1991. Origin and morphology of limestone caves. Geol. Soc. Am. Bull. 103, 1-21.

Pickering, R., Kramers, J.D., Hancox, P.J., de Ruiter, D., Woodhead, J., 2011. Contemporary flowstone development links early hominin bearing cave deposits in South Africa. Earth Planet. Sci. Lett. 306, 23-32.

Pickering, T.R., 2001. Taphonomy of the Swartkrans hominid postcrania and its bearing on issues of meat-eating and fire management. In: Stanford, C.B., Bunn, H.T. (Eds.), Meat-eating and Human Evolution. Oxford University, Oxford, pp. 33-51.

Pickering, T.R., Carlson, K.J., 2002. Baboon bone mineral densities: implications for the taphonomy of primate skeletons in South African cave sites. J, Archeol. Sci. 29, 883-896.

Pickering, T.R., Domínguez-Rodrigo, M., Egeland, C.P., Brain, C.K. 2004. Beyond leopards: tooth marks and the contribution of multiple carnivore taxa to the accumulation of the Swartkrans Member 3 fossil assemblage. J. Hum. Evol. 46, 595-604.

Pickering, T.R., Egeland, C.P., Domínguez-Rodrigo, M., Brain, C.K., Schnell, A.G., 2008. Testing the "shift in the balance of power" hypothesis at Swartkrans, South Africa: hominid cave use and subsistence behavior in the Early Pleistocene. J. Anthropol. Archaeol. 27, 30-45. 
Pickering et al.

Pickering, T.R., Heaton, J.L., Clarke, R.J., Sutton, M.B., Brain, C.K., Kuman, K., 2012. New hominid fossils from Member 1 of the Swartkrans Formation, South Africa. J. Hum. Evol. 62, 618-628.

Plavcan, J.M., 2000. Inferring social behavior from sexual dimorphism in the fossil record. J. Hum. Evol. 39, 327-344.

Plavcan, J.M., 2012. Sexual size dimorphism, canine dimorphism, and male-male competition in primates: where do humans fit in? Hum. Nat. 23, 45-67.

Robinson, J.T., 1952. The australopithecine-bearing deposits of the Sterkfontein area. Ann. Trans. Mus. 22: 1-19.

Robinson, J.T., 1956. The Dentition of the Australopithecinae. Transvaal Museum, Pretoria.

Ruff, C., 2002. Variation in human body size and shape. A. Rev. Anthropol. 31, 211-232.

Spocter, M.A., Manger, P.R., 2007. The use of cranial variables for the estimation of body mass in fossil hominins. Am. J. Phys. Anthropol. 134, 92-105.

Steudel, K., 1980. New estimates of early hominid body size. Am. J. Phys. Anthropol. 52, 63-70.

Susman, R.L. 1989. New hominid fossils from the Swartkrans Formation (1979 - 1986 excavations): postcranial specimens. Am. J. Phys. Anthropol. 79, 451-474. 


\section{Pickering et al.}

Susman, R.L. 1993. Hominid postcranial remains. In: Brain, C.K. (Ed.), Swartkrans: A Cave’s Chronicle of Early Man. Transvaal Museum, Pretoria, pp. 117-136.

Susman, R.L., de Ruiter, D., Brain, C.K., 2001. Recently identified postcranial remains of Paranthropus and early Homo from Swartkrans Cave, South Africa. J. Hum. Evol. 41, 607-629.

Sutton, M.B., Pickering, T.R., Pickering, R., Brain, C.K., Clarke, R.J., Heaton, J.L., Kuman, K., 2009. Newly discovered fossil- and artifact-bearing deposits, uranium-series ages and Plio-Pleistocene hominids at Swartkrans Cave, South Africa. J. Hum. Evol. 57, 688-696.

Suwa, G., Wood, B.A., White, T.D., 1994. Further analysis of mandibular molar crown areas in Pliocene and Early Pleistocene hominids. Am. J. Phys. Anthropol. 93, 407-426.

Suwa, G., White, T.D., Howell, F.C. 1996. Mandibular postcanine dentition from the Shungura Formation, Ethiopia: crown morphology, taxonomic allocations, and Plio-Pleistocene hominid evolution. Am. J. Phys. Anthropol. 101, 247-282.

Tobias, P.V., 1965. Australopithecus, Homo habilis, tool-using, and tool-making. S. Afr. Archaeol. Bull. 20, 167-192.

Tobias, P.V., 1967. The Cranium and Maxillary Dentition of Australopithecus (Zinjanthropus) boisei, Vol. II. Cambridge University Press, Cambridge. 
Pickering et al.

Tobias, P.V., 2000. The fossil hominids. In: Partridge, T.C., Maud, R.R. (Eds.), The Cenozoic of Southern Africa. Oxford Monographs on Geology and Geophysics. Oxford University Press, Oxford, pp. 252-276.

Ungar, P.S., Grine, F.E. 1991. Incisor size and wear in Australopithecus africanus and Paranthropus robustus. J. Hum. Evol. 20, 313-340.

Vrba, E.S., 1985. Early hominids in southern Africa: updated observations on chronological and ecological background. In: Tobias, P.V. (Ed.), Hominid Evolution: Past, Present and Future. Alan R. Liss, New York, pp. 195-200.

White, T.D., WoldeGabriel, G., Asfaw, B., Ambrose, S., Beyene, Y., Bernor, R.L., Boisserie, J.-R., Currie, B., Gilbert, H., Haile-Selassie, Y., Hart, W.K., Hlusko, L.J., Howell, F.C., Kono, R.T., Lehmann, T., Louchart, A., Lovejoy, C.O., Renne, P.R., Saegusa, H., Vrba, E.S., Wesselman, H., Suwa, G., 2006. Asa Issie, Aramis and the origin of Australopithecus. Nature 440, 883-889.

Wood, B.A., 1991. Koobi Fora Research Project IV: Hominid Cranial Remains from Koobi Fora. Clarendon Press, Oxford.

Wood, B.A., Abbott, S.A. 1983. Analysis of the dental morphology of Plio-Pleistocene hominids, I. Mandibular molars: crown area measurements and morphological traits. J. Anat. 136, 197-219.

Wood, B.A., Engleman, C.A., 1988. Analysis of the dental morphology of Plio-Pleistocene hominids, V. Maxillary postcanine tooth morphology. J. Anat. 161, 1-35. 
Pickering et al.

Wood, B.A., Abbott, S.A., Graham, S. 1983. Analysis of the dental morphology of Plio-Pleistocene hominids, II. Mandibular molars: study of cusp areas, fissure pattern and cross sectional shape of the crown. J. Anat. 137, 287-314.

\section{Figure Captions}

Figure 1. (a) Plan view of Swartkrans Cave illustrating most of the depositional units discussed in this paper (adapted from Brain, 1993b). Select 1 x $1 \mathrm{~m}$ excavation grid squares are indicated by intersecting N-S/E-W lines; site datum is at $0 \mathrm{~N}-\mathrm{S} 0 \mathrm{E}-\mathrm{W}$, represented by the intersection of the bold lines in the middle of the plan. Depositional bodies exposed aboveground include the Lower Bank (LB) of Member 1 and Member 3 (M3); in order to clarify positions of the LB and M3 deposits, Member 2 is removed in this plan but its interface with M3 includes excavation grid squares 1N 4W and 1S 3W. Relevant underground deposits include the "Talus Cone Deposit" (TCD) and the "Underground North Excavation" (UNE), which are represented in the linked stratigraphic columns (b) that show their relationships to previously described (Sutton et al., 2009) underground deposits of the Swartkrans Formation. The indicated SKW-4 flowstone was dated via U-Th to $110,000 \pm$ 
Pickering et al.

1,980 years old (Sutton et al., 2009). An informal view of an early stage of archaeological work in the UNE (north is roughly in the direction of the excavator in the right of the image) is shown in (c).

Figure 2. New anterior maxillary teeth from the Swartkrans Formation, with each fossil shown in labial (left of pair) and lingual (right of pair) views (bar scale $=1 \mathrm{~cm}):(a)$ SWT1/LB-19, a right deciduous central incisor from Member 1, Lower Bank; (b) SWT3-2433, a left deciduous central incisor from Member 3; (c) SWT1/LB-17, a right permanent canine from Member 1, Lower Bank; (d) SWT1/LB-18, a right permanent lateral incisor from Member 1, Lower Bank; (e) SWT3-1 a left permanent lateral incisor from Member 3; (f) SWT/UNE-1, a right permanent canine from the "Underground North Excavation".

Figure 3. New maxillary molars from the Swartkrans Formation, with each fossil shown in occlusal view and mesial side oriented to top of image (bar scale $=1 \mathrm{~cm}):($ a) SWT2/3-2, a right deciduous second molar from the Member 2/Member 3 interface; (b) SWT1/LB-20, a left deciduous second molar from Member 1, Lower Bank; (c) SWT/TC-5, a left permanent second molar from the "Talus Cone Deposit"; (d) SWT/TC-8, a right permanent first molar from the "Talus Cone Deposit".

Figure 4. New indeterminate postcanine tooth fragments from the "Talus Cone Deposit" of the Swartkrans Formation, each shown in occlusal view (left of pair) and in a view that reveals enamel thickness in natural cross-section, with the occlusal surface positioned towards the top of the image (right of pair) (white bar scale = $1 \mathrm{~cm}$ ): (a) SWT/TC-6; (b) SWT/TC-7. 
Pickering et al.

Figure 5. New permanent mandibular molars from the Swartkrans Formation, with each fossil shown in occlusal view and mesial side oriented to top of image (bar scale $=1 \mathrm{~cm}$ ): (a) SWT2/3-1, a right first molar from the Member 2/Member 3 interface; (b) SWT3-2, a right second molar from Member 3.

\section{Figure 6.}

a. Relationships between labiolingual and mesiodistal diameters of hominin permanent maxillary lateral incisors, including those for the new specimens, SWT1/LB-18 and SWT3-1. Here and in Figs. 6b-f and h, Australopithecus africanus = A. africanus sensu lato, which now includes specimens attributed to Australopithecus prometheus (Clarke, 2013).

b. Relationships between labiolingual and mesiodistal diameters of hominin permanent maxillary canines, including that for the new specimen, SWT/UNE-1.

c. Relationships between buccolingual and mesiodistal diameters of hominin permanent maxillary first molars, including that for the new specimen, SWT/TC-8.

d. Relationships between buccolingual and mesiodistal diameters of hominin permanent maxillary second molars, including that for the new specimen, SWT/TC-5.

e. Relationships between buccolingual and mesiodistal diameters of hominin permanent mandibular first molars, including that for the new specimen, SWT2/3-1.

f. Relationships between buccolingual and mesiodistal diameters of hominin permanent mandibular second molars, including that for the new specimen, SWT3-2.

g. Relationships between labiolingual and mesiodistal diameters of hominin deciduous maxillary central incisors, including those for the new specimens, SWT1/LB-19 and SWT2433.

h. Relationships between buccolingual and mesiodistal diameters of hominin deciduous maxillary second molars, including that for the new specimen, SWT2/3-2. 
Pickering et al.

Page 44 of 53 
Table 1. Comparative hominin tooth sample used in this study ${ }^{a, b}$

\begin{tabular}{|c|c|c|c|c|c|}
\hline Element & $\begin{array}{c}\text { South African } \\
\text { Australopithecusc }\end{array}$ & $\begin{array}{l}\text { Paranthropus } \\
\text { robustus }\end{array}$ & $\begin{array}{c}\text { Taxon } \\
\begin{array}{c}\text { South African } \\
\text { early } \text { Homo }^{\mathrm{e}}\end{array}\end{array}$ & $\begin{array}{c}\text { Paranthropus } \\
\text { boisei }\end{array}$ & $\begin{array}{l}\text { East African } \\
\text { early } \text { Homo }^{\mathrm{e}}\end{array}$ \\
\hline $\mathrm{I}^{2}$ & $\begin{array}{c}\text { MLD 11, 23; } \\
\text { Sts 24, 52, 1512; } \\
\text { SWT 23, 42, 183, } \\
252,498\end{array}$ & $\begin{array}{c}\text { DNH 7, 25, 41; } \\
\text { SK 52, 55, 65, 66, } \\
\text { 70, 71; SKX 1788 }\end{array}$ & $\begin{array}{c}\text { DNH 45; } \\
\text { SK 27, 847; } \\
\text { SWT 75, 151; } \\
\text { SKX 610 } \\
\end{array}$ & $\begin{array}{c}\text { KNM-ER 1171, } \\
\text { 17760; } \\
\text { KNM-WT 17400; } \\
\text { OH } 5\end{array}$ & $\begin{array}{c}\text { KNM-ER 808; } \\
\text { KNM-WT 15000; } \\
\text { OH 6, 16, 39, } 65\end{array}$ \\
\hline $\mathrm{C}^{1}$ & $\begin{array}{c}\text { MH 1; MLD 11; } \\
\text { Sts 3, 48, 52, } \\
\text { 1512, 1527; SWT } \\
\text { 183, 252, 287, } \\
369,410,498,536\end{array}$ & $\begin{array}{c}\text { DNH 7, 28, 41, } \\
\text { 52, 73, 82; SK 4, } \\
38,48,55,65,83, \\
84,85,86,92,93, \\
95 ; \text { SKX 162, 312, } \\
\text { 25296, 28724; } \\
\text { SWT1/HR 1 }\end{array}$ & $\begin{array}{c}\text { SK 27; SWT } \\
75,151\end{array}$ & $\begin{array}{c}\text { KNM-CH 1; } \\
\text { KNM-ER 802, } \\
\text { 816, 1171; } \\
\text { KNM-WT } 17400 ; \\
\text { OH } 5\end{array}$ & $\begin{array}{c}\text { KNM-ER 1590, } \\
\text { 1805, 1813; } \\
\text { KNM-WT 15000; } \\
\text { OH 15, 16, 39, } 65\end{array}$ \\
\hline $\mathrm{M}^{1}$ & $\begin{array}{c}\text { MH 1; MLD 6; } \\
\text { Sts 1, 8, 17, 21, 24, } \\
\text { 28, 43, 52, 53, 56, } \\
\text { 57, 61, 1511, } \\
\text { 1512; } \\
\text { SWT 9, 59, 73, } \\
\text { 183, 208, 252, } \\
\text { 280, 402, 450, } \\
\text { 498; Taung } 1\end{array}$ & $\begin{array}{c}\text { CD 5774; DNH 4, } \\
\text { 7, 14, 57, 60; } \\
\text { KB 5063, 5383; } \\
\text { SK 8, 13, 17, 47, } \\
48,49,52,55 \\
\text { 102, 829, 832, } \\
838,872,1590 \\
\text { 1591; SKW 11, } \\
\text { 14133; } \\
\text { SKX 3601; } \\
\text { TM } 15171601\end{array}$ & $\begin{array}{c}\text { DNH 39, 62, } \\
\text { 70; SE 255; } \\
\text { SK 27; } \\
\text { SKW 3114; } \\
\text { SKX 268, 334; } \\
\text { SWT 151 }\end{array}$ & $\begin{array}{c}\text { KNM-CH 1; } \\
\text { KNM-ER 733, } \\
\text { 1804; } \\
\text { KNM-WT } 17400 ; \\
\text { OH } 5\end{array}$ & $\begin{array}{c}\text { KNM-ER 1590, } \\
\text { 1805, 1813, } \\
\text { 3733, 42703; } \\
\text { KNM-WT 15000; } \\
\text { OH 6, 13, 16, 21, } \\
24,39,41,44,45, \\
65\end{array}$ \\
\hline
\end{tabular}




\begin{tabular}{|c|c|c|c|c|c|}
\hline $\mathrm{M}^{2}$ & $\begin{array}{c}\text { MH 1; MLD 6, 28; } \\
\text { Sts 1, 8, 12, 17, 22, } \\
28,30,32,37,52 \\
\text { 53, 56, 61, 1511; } \\
\text { SWT 13, 19, 71, } \\
\text { 73, 183, 188, 204, } \\
\text { 252, 259, 280, } \\
447,498\end{array}$ & $\begin{array}{c}\text { DNH 1, 3, 7, 22, } \\
\text { 74; SK 13, 14, 46, } \\
\text { 47, 48, 49, 83, 98, } \\
\text { 826, 831, 834, } \\
\text { 837, 14129; } \\
\text { SKW 8, 11, 14, } \\
\text { 29; SKX 3354; } \\
\text { TM } 1517\end{array}$ & $\begin{array}{c}\text { SK 27; } \\
\text { Sts 1508; } \\
\text { SWT 151 }\end{array}$ & $\begin{array}{c}\text { KNM-CH } 1 ; \\
\text { KNM-ER 1171, } \\
\text { 1804; } \\
\text { KNM-WT } 17400 ; \\
\text { OH } 5\end{array}$ & $\begin{array}{c}\text { KNM-ER 1590, } \\
\text { 1805, 1808, } \\
\text { 1813, 3733, } \\
\text { 42703; } \\
\text { KNM-WT 15000; } \\
\text { OH 4, 13, 16, } 39\end{array}$ \\
\hline $\mathrm{M}_{1}$ & $\begin{array}{l}\text { MH 1, 2; MLD 2, } \\
\text { 18, 40; Sts 9, 18, } \\
\text { 24, 52; SWT 1, } \\
\text { 106, 123, 131, } \\
\text { 142, 145, 193, } \\
246,291,309, \\
327,364,384, \\
404,421,491 \\
498,537\end{array}$ & $\begin{array}{c}\text { DNH 7, 8, 46, 60; } \\
\text { KB 5223; SK 6, } \\
\text { 23, 25, 34, 55, 61, } \\
63,104,828,838, \\
843,846,1587, \\
\text { 1588, 3974, } \\
\text { 5013, 5023; } \\
\text { SKW 5, 4767; } \\
\text { SKX 4446; } \\
\text { SWT 566; } \\
\text { TM 1517, 1536 }\end{array}$ & $\begin{array}{c}\text { DNH } 35,67 ; \\
\text { SK 15; } \\
\text { SKX 258; } \\
\text { SWT 151 }\end{array}$ & $\begin{array}{c}\text { KNM-ER 403, } \\
\text { 729, 802, 818, } \\
\text { 1509, 1816, } \\
\text { 1820, 3230, } \\
\text { 3737, 3890, } \\
\text { 15930; OH 30; } \\
\text { Omo 75-14, L7A- } \\
\text { 125; Peninj 1 }\end{array}$ & $\begin{array}{c}\text { Garba IV; } \\
\text { KNM-ER 730, } \\
\text { 806, 820, 992, } \\
\text { 1482, 1502, } \\
\text { 1507, 1801, } \\
\text { 1802; KNM-WT } \\
\text { 15000; } \\
\text { OH 7, 13, 16, 37; } \\
\text { UR 501 }\end{array}$ \\
\hline
\end{tabular}




\begin{tabular}{|c|c|c|c|c|c|}
\hline $\mathrm{M}_{2}$ & $\begin{array}{c}\text { MH 1,2; MLD 2, } \\
\text { 18, 24, 40; Sts 4, } \\
\text { 6, 23, 52, 1515; } \\
\text { SWT 3, 14, 61, } \\
\text { 72, 109, 120, 134, } \\
\text { 142, 212, 213, } \\
\text { 234, 285, 295, } \\
\text { 308, 327, 384, } \\
\text { 385, 404, 412, } \\
\text { 424, 491, 498, } \\
\text { 529, 537, 555, } \\
560\end{array}$ & $\begin{array}{c}\text { DNH 7, 8, 19, 21, } \\
\text { 51, 60, 68; SK 1, } \\
\text { 5, 6, 23, 25, 34, } \\
37,55,843,858 \\
\text { 1586, 1587, } \\
\text { 1648, 3976; } \\
\text { SKW 5, 4769; } \\
\text { SKX 4446, } \\
\text { 19892; TM 1600 }\end{array}$ & SK 15,45 & $\begin{array}{c}\text { KNM-ER 403, } \\
\text { 404, 729, 801, } \\
\text { 818, 1171, 1816, } \\
\text { 3230, 5679, } \\
\text { 15930; OH 38; } \\
\text { Omo 47-46, 75- } \\
\text { 14, L427-7, L7A- } \\
\text { 125; Peninj 1 }\end{array}$ & $\begin{array}{c}\text { KNM-ER 806, } \\
\text { 992, 1482, 1802, } \\
\text { 1805, 1808; } \\
\text { KNM-WT 15000; } \\
\text { OH 7, 13, 16, 37; } \\
\text { UR 501 }\end{array}$ \\
\hline $\mathrm{di}^{1}$ & & DNH 47; SK 8 & & & KNM-ER 808 \\
\hline $\mathrm{dm}^{2}$ & $\begin{array}{c}\text { Sts } 2,24 ; \text { SWT } \\
\text { 59, 103, 488, } \\
\text { Taung } 1\end{array}$ & $\begin{array}{c}\text { CD 1634; } \\
\text { DNH 30, 42, 47, } \\
\text { 57; SK 55, 90, } \\
\text { 838, 839, 1595; } \\
\text { SKX 32832 }\end{array}$ & $\begin{array}{c}\text { SE 255; SK 27; } \\
\text { SKX 267; } \\
\text { SWT 151 }\end{array}$ & $\mathbf{O H} 3,30$ & $\begin{array}{c}\text { KNM-ER 1590; } \\
\text { OH } 39\end{array}$ \\
\hline
\end{tabular}

a. Data from Moggi-Cecchi et al. $(2006,2010)$ and courtesy of Jacopo Moggi-Cecchi.

b. Abbreviations: $\mathrm{C}^{1}=$ permanent maxillary canine; $\mathrm{CD}=$ Cooper's $\mathrm{D} ; \mathrm{di}^{1}=$ deciduous maxillary central incisor; $\mathrm{dm}^{2}=\mathrm{deciduous}$ maxillary second molar; DNH = Drimolen Hominin; $\mathrm{I}^{2}=$ permanent maxillary lateral incisor; KNM-CH = Kenya National Museum, Chesowanja; KNM-ER = Kenya National Museum, East Rudolf; KNM-WT = Kenya National Museum, West Turkana; KB = Kromdraai B; $\mathrm{M}^{1}$ = permanent maxillary first molar; $\mathrm{M}^{2}=$ permanent maxillary second molar; $\mathrm{M}_{1}=$ permanent mandibular first molar; $\mathrm{M}_{2}=$ permanent mandibular second molar; $\mathrm{MH}=$ Malapa Hominin; MLD = Makapansgat Limeworks Dump; $\mathrm{OH}=\mathrm{Olduvai}$ Hominid; SE = Sterkfontein Extension Site; SK = Swartkrans; SKW = Swartkrans Witwatersrand; SKX = Swartkrans Excavations; Sts = Sterkfontein Type Site; SWT = Sterkfontein Witwatersrand; SWT1/HR = Swartkrans (Transvaal) Member 1/Hanging Remnant; TM = Transvaal Museum; UR = Uraha.

c. Includes specimens attributed to A. africanus, A. prometheus and A. sediba. 
Pickering et al.

d. Includes specimens attributed by some authors to P. crassidens (e.g., Broom, 1949; Howell, 1978; Grine, 1982, 1984, 1985, 1993; Jungers and Grine, 1986).

e. Includes specimens attributed variably to Homo sp. indet., H. ergaster, H. erectus, H. rudolfensis and H. habilis sensu lato; the last taxon probably includes at least several specimens that are actually gracile australopiths (e.g., Leakey, 1973; Clarke, 2008, 2012). 
Pickering et al.

Table 2. New Hominin Fossils from the Swartkrans Formationa

\begin{tabular}{|c|c|c|c|c|}
\hline Specimen & Taxon & Element & Depositional Unit & Excavation coordinates ${ }^{b}$ \\
\hline SWT1/LB-17 & $\begin{array}{l}\text { Hominidae gen. et } \\
\text { sp. indet. }\end{array}$ & $\mathrm{RC}^{1}$ & Member 1, Lower Bank & $2 \mathrm{~N} 6 \mathrm{E}(\mathrm{B}), 94.300-94.200$ \\
\hline SWT1/LB-18 & $\begin{array}{l}\text { Paranthropus } \\
\text { robustus }\end{array}$ & $\mathrm{RI}^{2}$ & Member 1, Lower Bank & $3 \mathrm{~N} 6 \mathrm{E}(\mathrm{A}), 93.400-93.300$ \\
\hline SWT1/LB-19 & $\begin{array}{l}\text { Paranthropus } \\
\text { robustus }\end{array}$ & $\operatorname{Rdi}^{1}$ & Member 1, Lower Bank & 2N 7E (A), 94.400-94.300 \\
\hline SWT1/LB-20 & $\begin{array}{l}\text { Paranthropus } \\
\quad \text { robustus }\end{array}$ & $\mathrm{Ldm}^{2}$ & Member 1, Lower Bank & $3 \mathrm{~N} 6 \mathrm{E}(\mathrm{A}), 93.600-93.500$ \\
\hline SWT/TC-5 & $\begin{array}{l}\text { Paranthropus } \\
\quad \text { robustus }\end{array}$ & $\mathrm{LM}^{2}$ & "Talus Cone Deposit" & $10 \mathrm{~N}$ 17E (D), 89.700-89.600 \\
\hline SWT/TC-6 & $\begin{array}{l}\text { Hominidae gen. et } \\
\text { sp. indet. }\end{array}$ & $\mathrm{P}_{4}(?)$ & "Talus Cone Deposit" & $11 \mathrm{~N} 13 \mathrm{E}(\mathrm{D}), 89.450-89.350$ \\
\hline SWT/TC-7 & $\begin{array}{l}\text { Hominidae gen. et } \\
\text { sp. indet. }\end{array}$ & $\mathrm{PC}$ & "Talus Cone Deposit" & $11 \mathrm{~N} 13 \mathrm{E}$ (B) $89.250-89.150$ \\
\hline SWT/TC-8 & $\begin{array}{l}\text { Paranthropus } \\
\quad \text { robustus }\end{array}$ & $\mathrm{RM}^{1}$ & "Talus Cone Deposit" & $11 \mathrm{~N} 13 \mathrm{E}$ (B) $89.050-88.950$ \\
\hline SWT2/3-1 & $\begin{array}{l}\text { Paranthropus } \\
\quad \text { robustus }\end{array}$ & $\mathrm{RM}_{1}$ & Member $2 / 3$ interface & $1 \mathrm{~N} 4 \mathrm{~W}$ (all) 95.800-95.500 \\
\hline SWT2/3-2 & $\begin{array}{l}\text { Paranthropus } \\
\text { robustus }\end{array}$ & $\mathrm{Rdm}^{2}$ & Member $2 / 3$ interface & 1S 3W (all) 95.850-95.750 \\
\hline SWT3-1 & $\begin{array}{l}\text { Paranthropus } \\
\quad \text { robustus }\end{array}$ & $\mathrm{LI}^{2}$ & Member 3 & 5S 4W (all) 92.000-91.500 \\
\hline SWT3-2 & $\begin{array}{l}\text { Paranthropus } \\
\quad \text { robustus }\end{array}$ & $\mathrm{RM}_{2}$ & Member 3 & 4S 5W (all) 96.800-96.700 \\
\hline SWT3-2433 & $\begin{array}{l}\text { Paranthropus } \\
\quad \text { robustus }\end{array}$ & $\operatorname{Ldi}^{1}$ & Member 3 & 5S 4W (all) 92.000-91.500 \\
\hline SWT/UNE-1 & $\begin{array}{l}\text { Paranthropus } \\
\text { robustus }\end{array}$ & $\mathrm{RC}^{1}$ & $\begin{array}{l}\text { "Underground North } \\
\text { Excavation" }\end{array}$ & 18N 9E (D) 88.300 \\
\hline
\end{tabular}

a. Abbreviations: $\mathrm{C}^{1}=$ permanent maxillary canine; $\mathrm{di}^{1}=$ deciduous maxillary central incisor; $\mathrm{dm}^{2}=$ deciduous maxillary second molar; $\mathrm{I}^{2}=$ permanent maxillary lateral 
Pickering et al.

incisor; $\mathrm{L}=$ left; $\mathrm{M}^{1}=$ permanent maxillary first molar; $\mathrm{M}^{2}=$ permanent maxillary second molar; $\mathrm{M}_{1}=$ permanent mandibular first molar; $\mathrm{M}_{2}=$ permanent mandibular second molar; $\mathrm{P}_{4}=$ permanent mandibular fourth premolar; $\mathrm{PC}=$ unidentifiable postcanine tooth fragment; $\mathrm{R}=$ right; (?) = tentative attribution.

b. Information in parentheses refers to $50 \mathrm{~cm} \times 50 \mathrm{~cm}$ excavation quads, with: $\mathrm{A}=\mathrm{NW}$ quad; $B=$ NE quad; $C$ = SW quad; $D=S E$ quad; all = all quads. Depths are recorded in meters below a site surface datum of $100 \mathrm{~m}$. 
Pickering et al.

Table 3a. Mesiodistal (MD) diameters (mm) of newly recovered, measurable hominin teeth from the Swartkrans Formation compared to summary statistics for Swartkrans and other Paranthropus robustus teetha,b

\begin{tabular}{|c|c|c|c|c|c|}
\hline Specimen & Element & MD & $\begin{array}{l}\text { Swartkrans } P \text {, robustus } \\
\text { mean, } S D(n, \text { range })^{c}\end{array}$ & $\begin{array}{l}\text { Kromdraai } P \text {. robustus } \\
\text { mean, } S D(n, \text { range)c }\end{array}$ & $\begin{array}{l}\text { Drimolen } P \text {, robustus } \\
\text { mean, } S D(n, \text { range) }\end{array}$ \\
\hline SWT1/LB-18 & $\mathrm{I}^{2}$ & $5.9^{*}$ & \multirow[b]{2}{*}{$6.7,0.7(7,5.9-8.1)$} & & \multirow[b]{2}{*}{$5.7,0.7(3,5.0-6.3)$} \\
\hline SWT3-1 & $\mathrm{I}^{2}$ & & & & \\
\hline SWT/UNE-1 & $\mathrm{C}^{1}$ & 7.8 & $8.5,0.6(17,7.4-9.7)$ & & $8.7,0.8(5,7.9-9.9)$ \\
\hline SWT/TC-8 & $\mathrm{M}^{1}$ & {$[15.0]$} & $13.3,0.5(18,12.4-13.9)$ & $12.9,0.9(4,11.7-13.8)$ & $12.8,0.8(5,12.0-14.1)$ \\
\hline SWT/TC-5 & $\mathrm{M}^{2}$ & 13.0 & $14.2,0.9(18,12.8-15.7)$ & $13.7,0.0(13.7-13.7)$ & $13.1,1.3(5,11.6-15.0)$ \\
\hline SWT2/3-1 & $\mathrm{M}_{1}$ & 13.7 & $14.9,0.8(22,13.0-16.7)$ & $14.0,1.0(3,12.9-14.8)$ & $14.4,0.8(6,13.4-15.7)$ \\
\hline SWT3-2 & $\mathrm{M}_{2}$ & $17.5^{*}$ & $16.5,0.8(16,15.1-17.9)$ & $15.4,0.0(1,15.4-15.4)$ & $15.7,1.6(7,13.4-17.2)$ \\
\hline SWT1/LB-19 & $\mathrm{di}^{1}$ & & \multirow{2}{*}{$6.7,0.0(1,6.7-6.7)$} & & \multirow[t]{2}{*}{$6.3,0.0(1,6.3-6.3)$} \\
\hline SWT3-2433 & $\mathrm{di}^{1}$ & 7.6 & & & \\
\hline SWT1/LB-20 & $\mathrm{dm}^{2}$ & $9.9^{*}$ & \multirow[b]{2}{*}{$11.0,0.4(6,10.4-11.4)$} & & \multirow[b]{2}{*}{$11.5,0.4(11.1-11.8)$} \\
\hline SWT2/3-2 & $\mathrm{dm}^{2}$ & $9.9^{*}$ & & & \\
\hline
\end{tabular}


Table 3b. Labio/buccolingual (LL/BL) diameters (mm) of newly recovered, measurable hominin teeth from the Swartkrans Formation compared to summary statistics for Swartkrans and other Paranthropus robustus teetha,b

\begin{tabular}{|c|c|c|c|c|c|}
\hline Specimen & Element & LL/BL & $\begin{array}{l}\text { Swartkrans } P \text {. robustus } \\
\text { mean, SD }(n, \text { range) }\end{array}$ & $\begin{array}{l}\text { Kromdraai } P \text {, robustus } \\
\text { mean, SD }(n, \text { range)c }\end{array}$ & $\begin{array}{l}\text { Drimolen } P \text {. robustus } \\
\text { mean, SD (n, range)c }\end{array}$ \\
\hline SWT1/LB-18 & $\mathrm{I}^{2}$ & $6.3^{*}$ & \multirow[b]{2}{*}{$6.6,0.7(7,5.8-7.9)$} & & \multirow[b]{2}{*}{$6.1,0.8(3,5.4-7.0)$} \\
\hline SWT3-1 & $\mathrm{I}^{2}$ & & & & \\
\hline SWT/UNE-1 & $\mathrm{C}^{1}$ & 9.2 & $9.4,0.7(17,8.4-11.1)$ & & $8.8,0.8(7,7.9-9.9)$ \\
\hline SWT/TC-8 & $\mathrm{M}^{1}$ & [15.8] & $14.9,0.6(18,14.4-16.8)$ & $14.0,0.9(4,13.2-15.1)$ & $14.2,0.7(5,13.6-15.2)$ \\
\hline SWT/TC-5 & $\mathrm{M}^{2}$ & 14.3 & $16.0,0.8(18,14.5-17.0)$ & $16.1,0.0(1,16.0-16.0)$ & $14.7,0.8(5,14.0-16.0)$ \\
\hline SWT2/3-1 & $\mathrm{M}_{1}$ & 13.0 & $13.7,0.9(21,12.0-15.5)$ & $12.5,0.8(3,11.7-13.2)$ & $13.1,1.0(5,11.9-14.5)$ \\
\hline SWT3-2 & $\mathrm{M}_{2}$ & $16.0^{*}$ & $15.0,1.0(18,13.0-16.5)$ & $14.7,0.0(1,14.7-14.7)$ & $14.1,0.9(6,13.0-15.2)$ \\
\hline SWT1/LB-19 & $\mathrm{di}^{1}$ & & $5.2,0.0(1,5.2-5.2)$ & & $4.3,0.0(1,4.3-4.3)$ \\
\hline SWT3-2433 & $\mathrm{di}^{1}$ & 4.8 & & & \\
\hline SWT1/LB-20 & $\mathrm{dm}^{2}$ & - & & & \\
\hline SWT2/3-2 & $\mathrm{dm}^{2}$ & $11.5^{*}$ & $12.1,0.4(6,11.5-12.7)$ & & $12.0,0.7(3,11.3-12.7)$ \\
\hline
\end{tabular}

a. Abbreviations: $\mathrm{C}^{1}=$ permanent maxillary canine; $\mathrm{di}^{1}=$ deciduous maxillary central incisor; $\mathrm{dm}^{1}=$ deciduous maxillary first molar; $\mathrm{dm}^{2}=$ deciduous maxillary second molar; $\mathrm{I}^{2}=$ permanent maxillary lateral incisor; $\mathrm{M}^{1}$ = permanent maxillary first molar; $\mathrm{M}^{2}$ = permanent maxillary second molar; $\mathrm{M}_{1}=$ permanent mandibular first molar; $\mathrm{M}_{2}=$ permanent mandibular second molar. 
Pickering et al.

b. Values followed by asterisks are associated with specimens that evince moderate to heavy wear but are uncorrected for that wear; values in brackets are estimates.

c. Data from Moggi-Cecchi et al. (2010). 


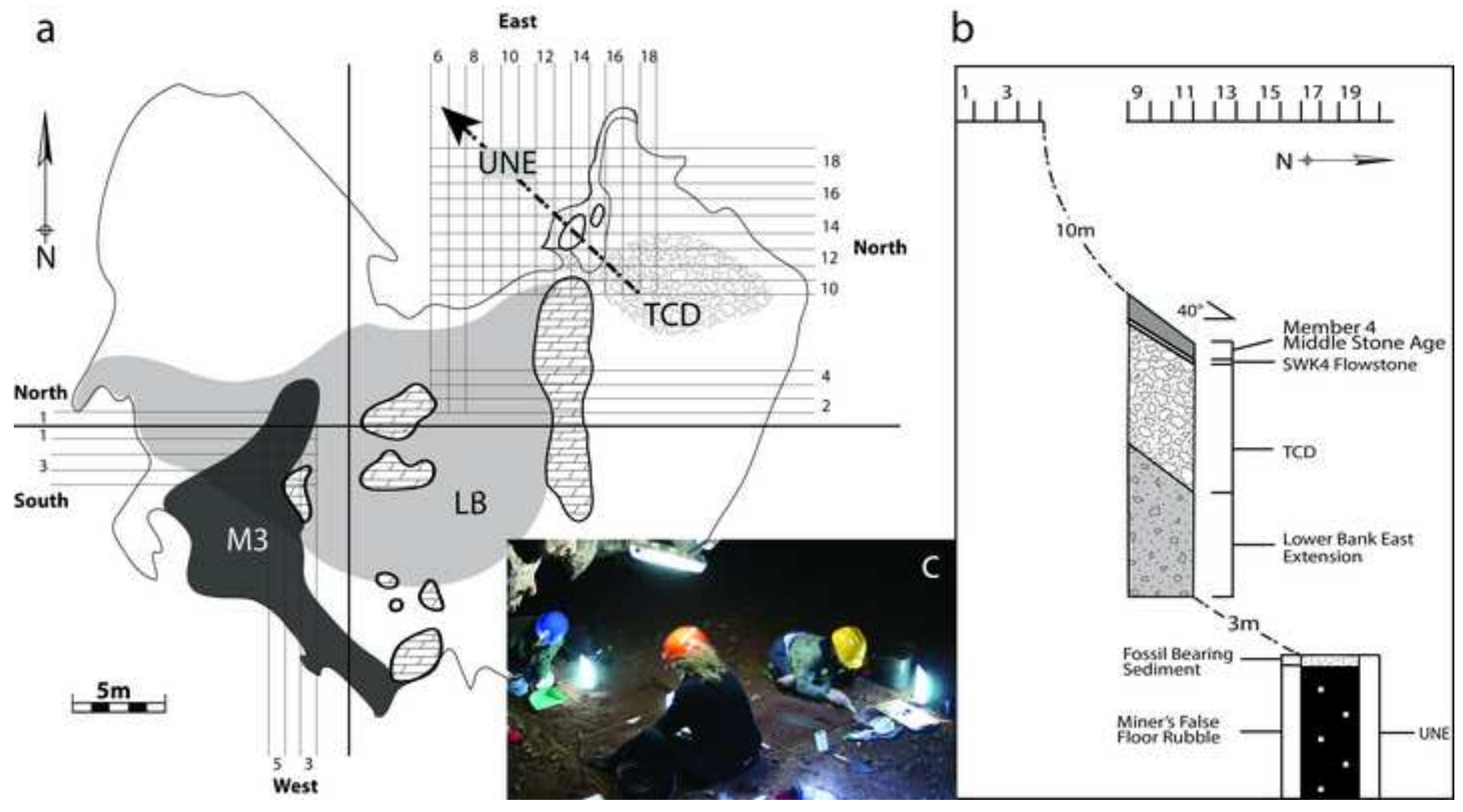



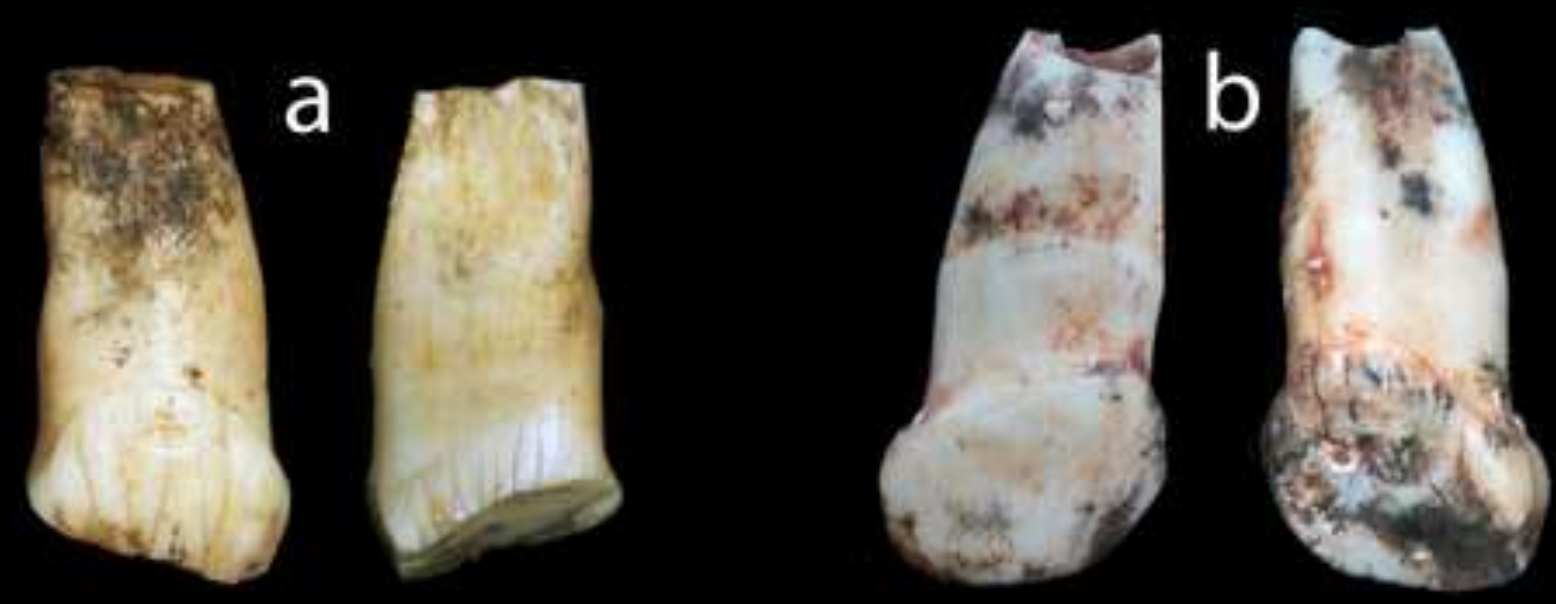

C
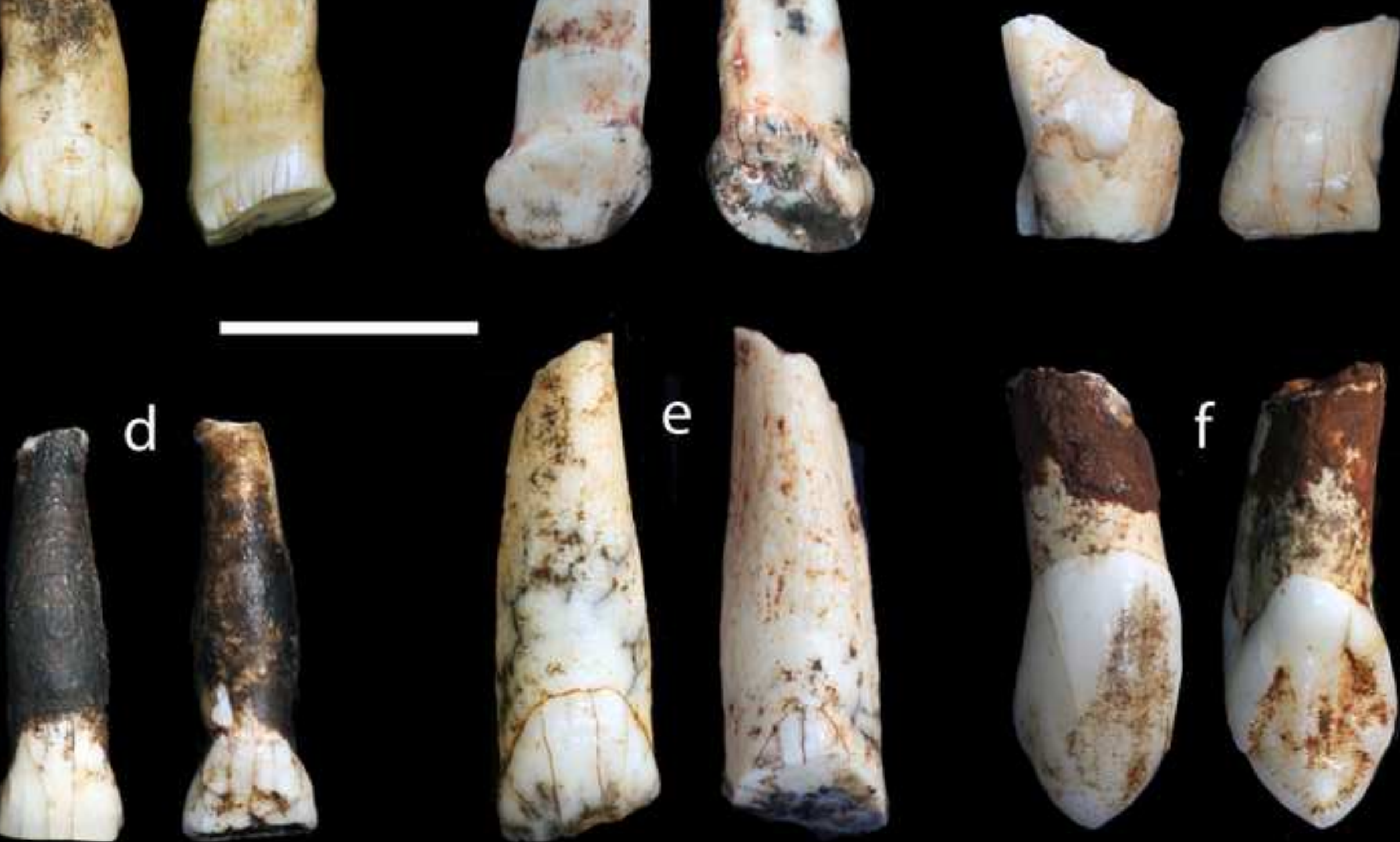
a

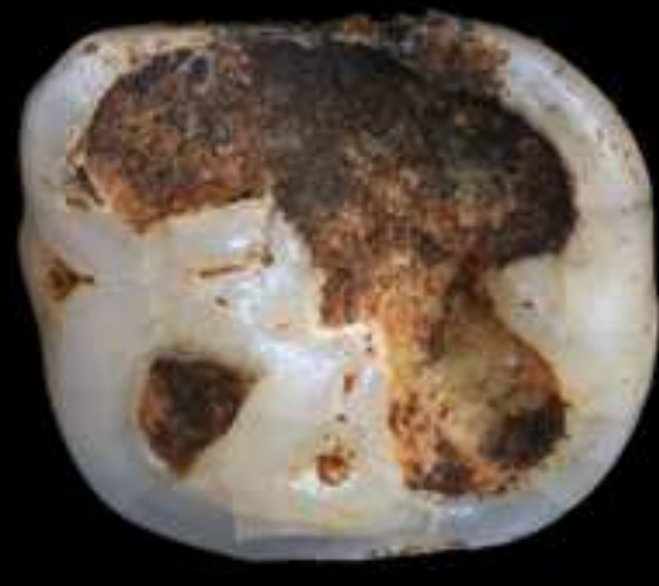

C b

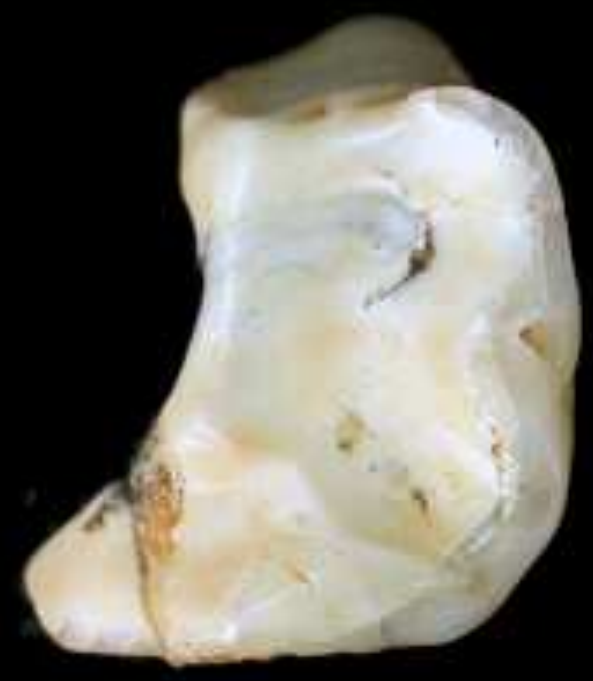

d

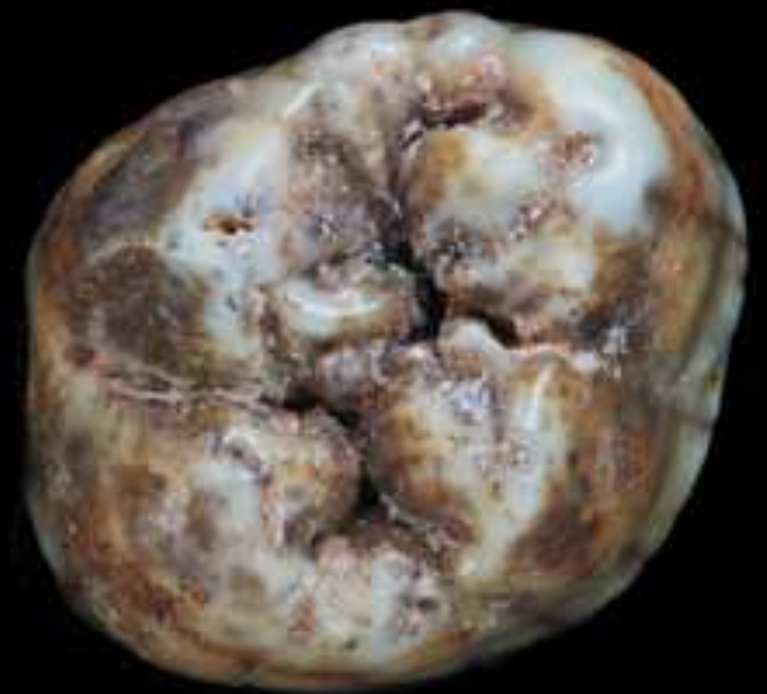

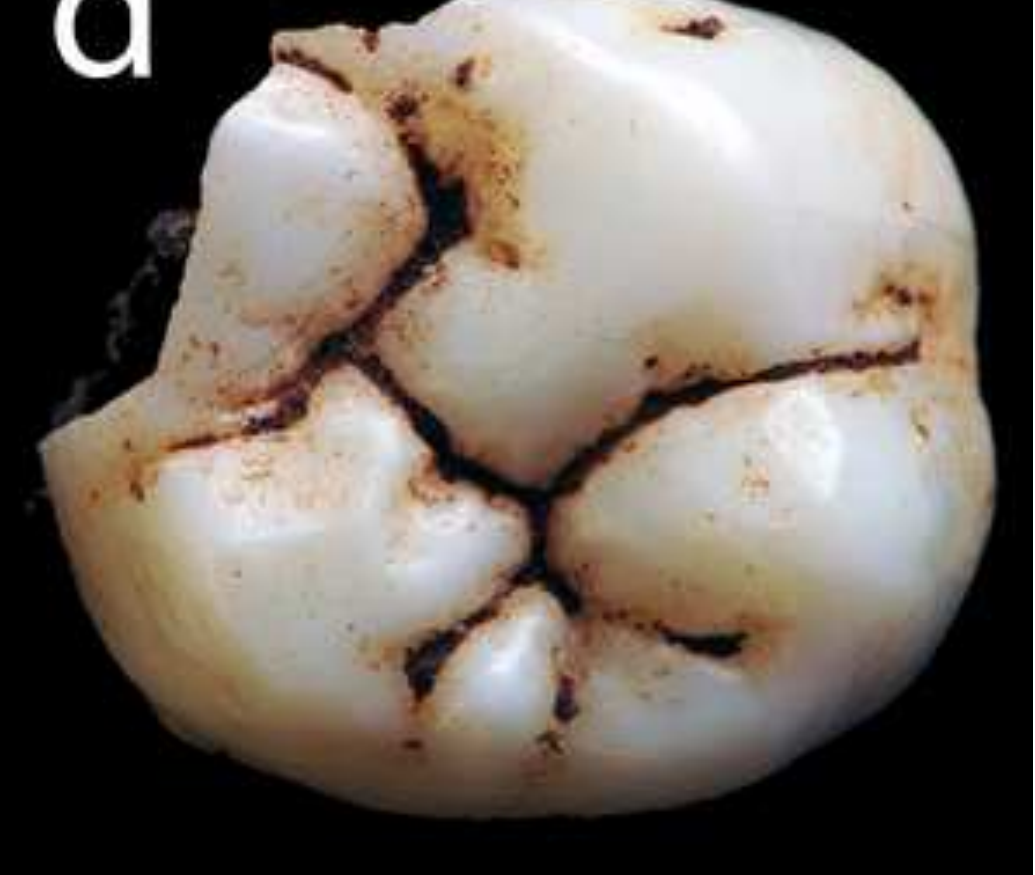


a

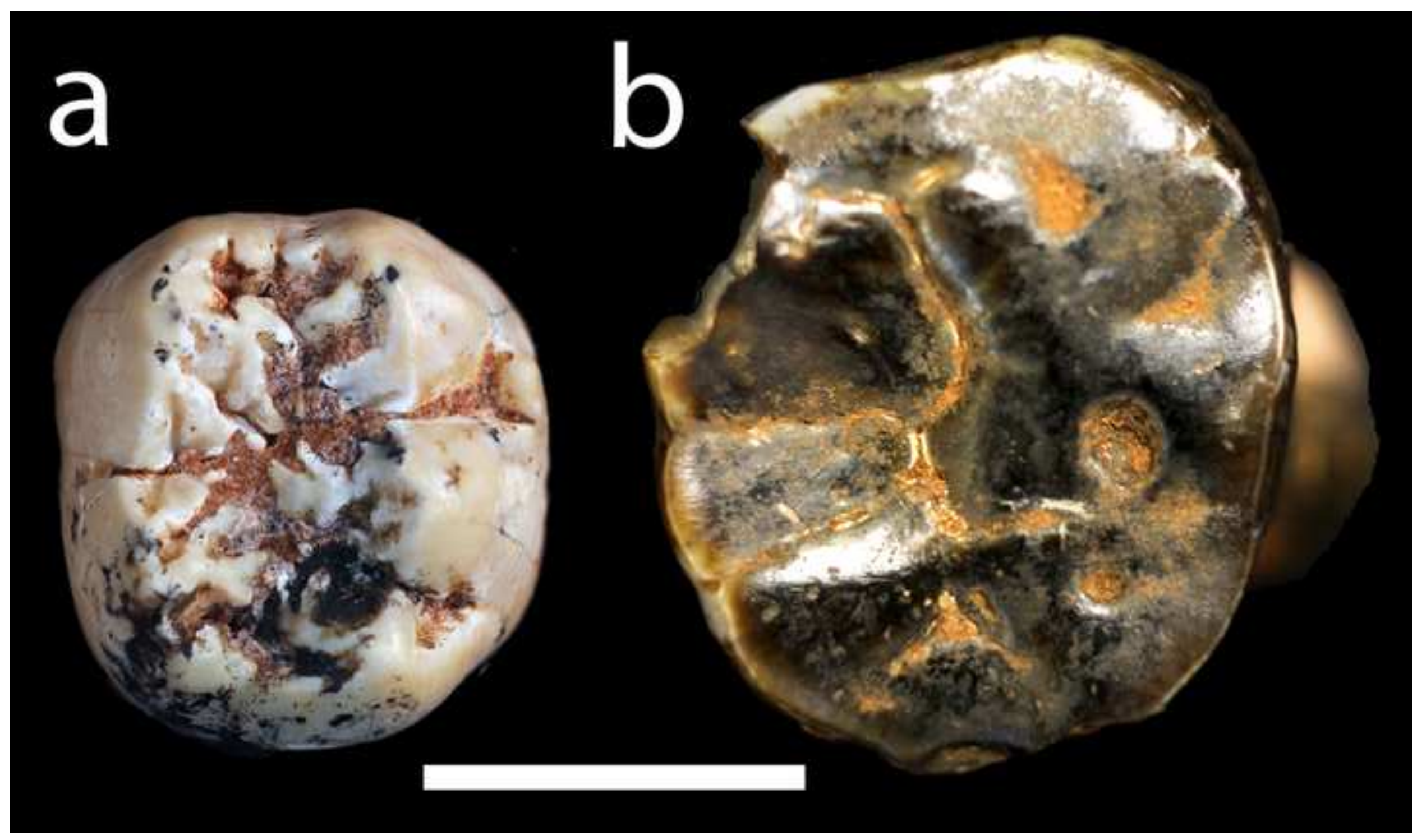

b

(n)

sot.

$2+2 \times-1$
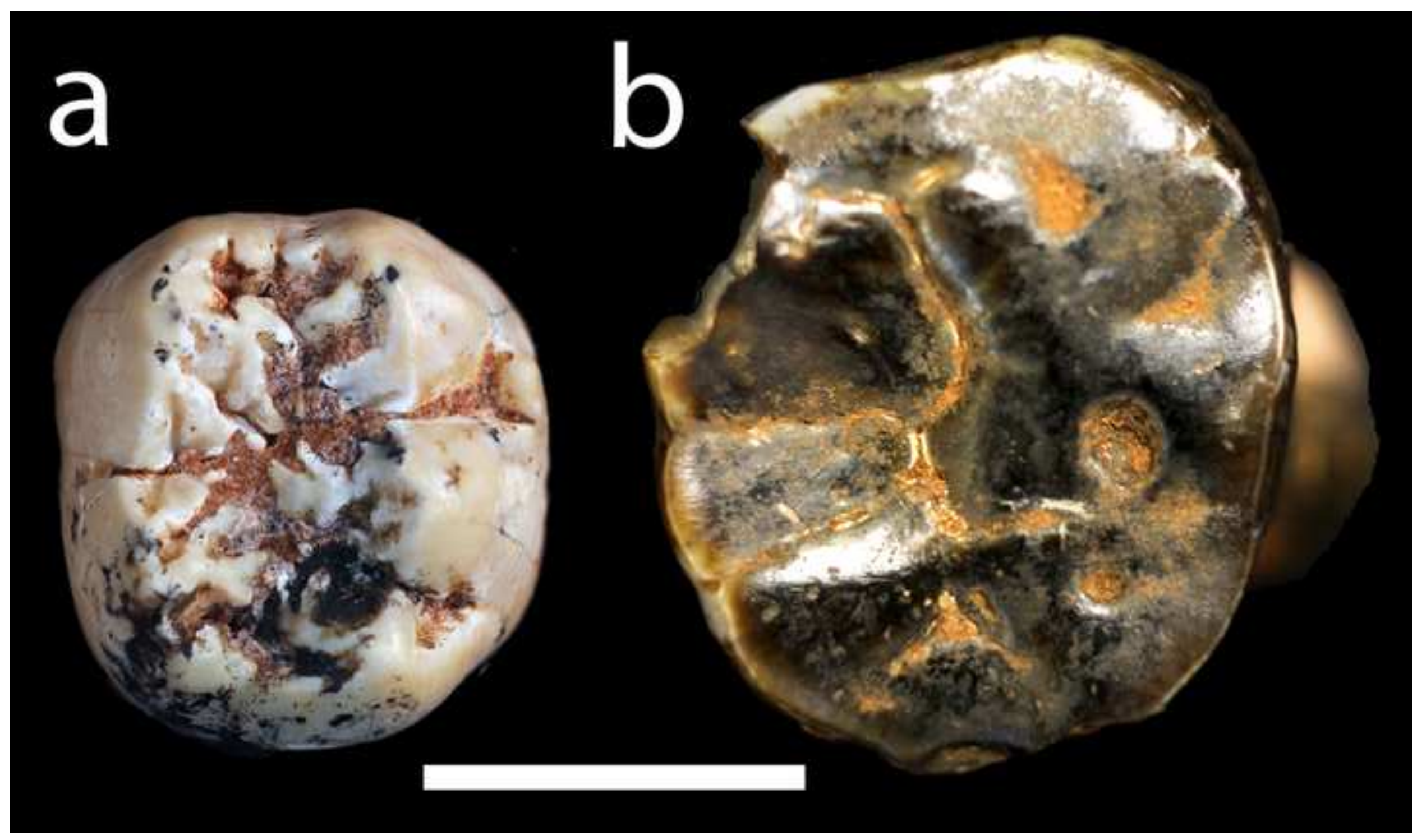

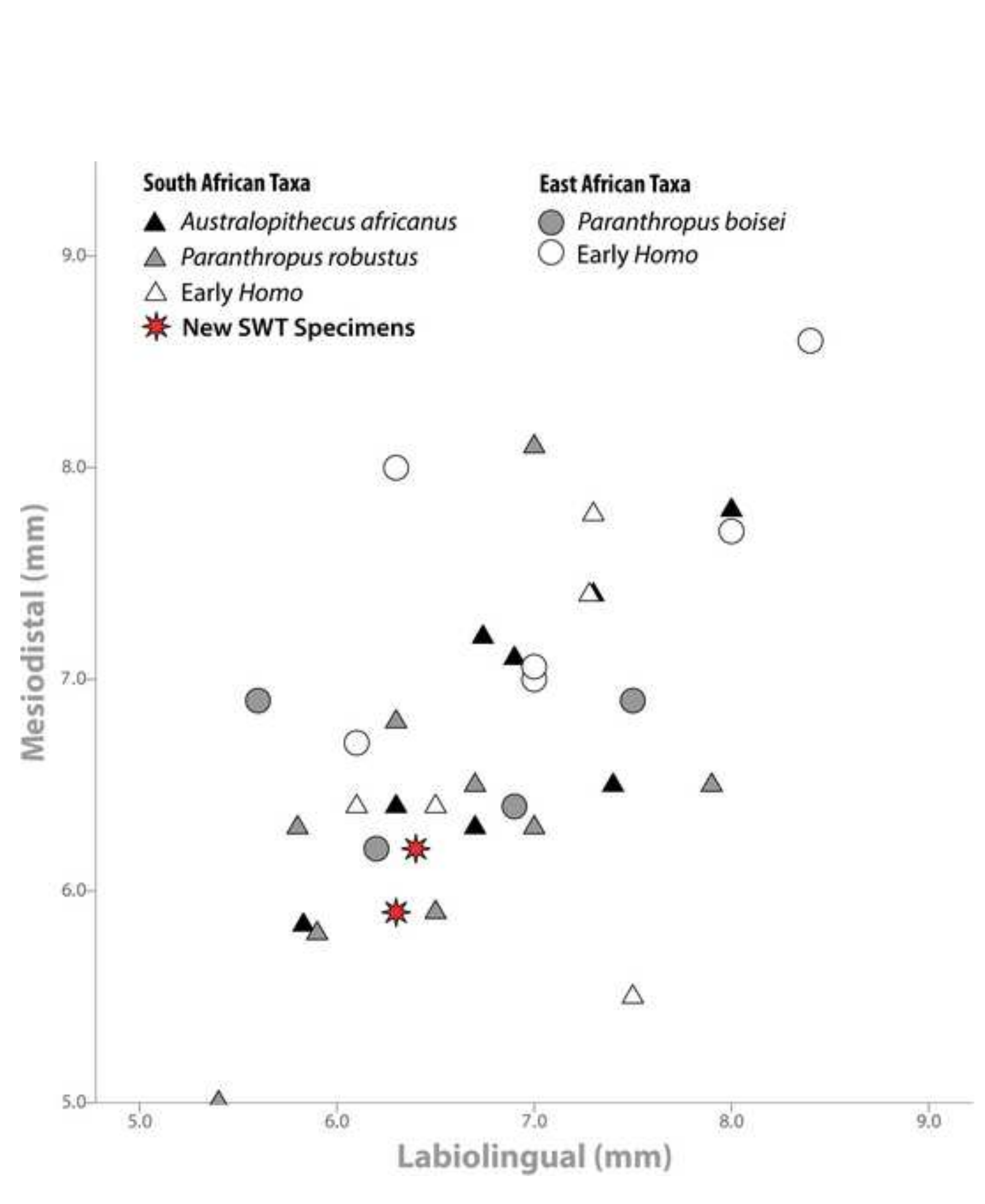

-
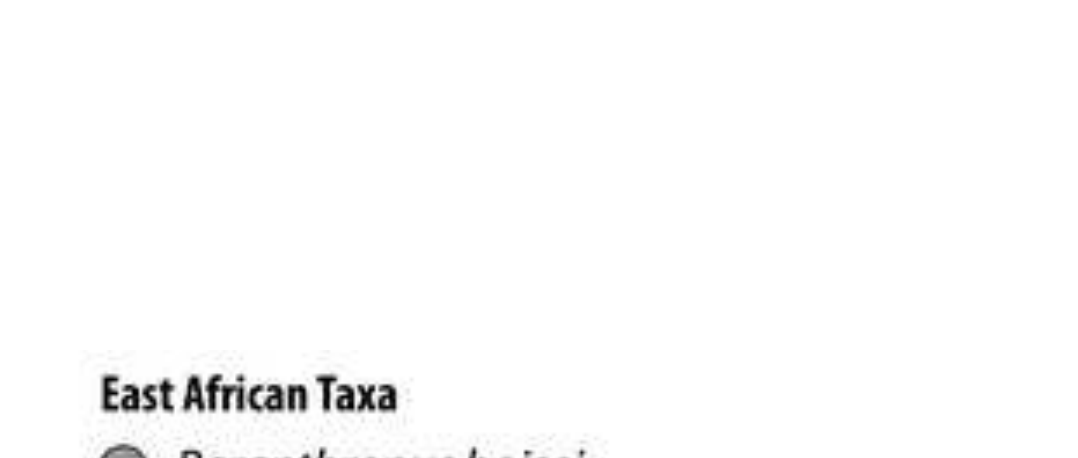

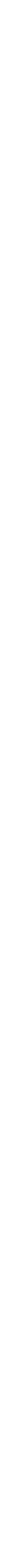
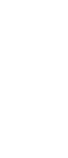

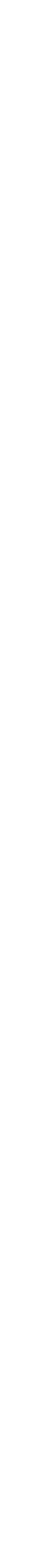
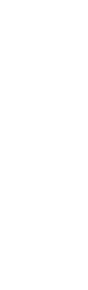

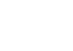

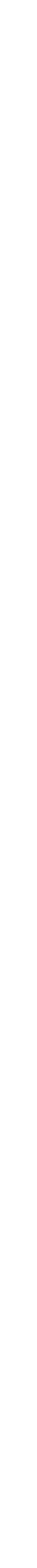

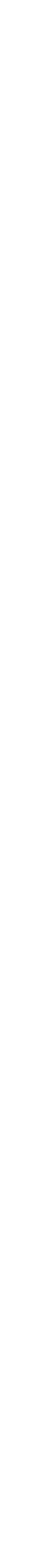

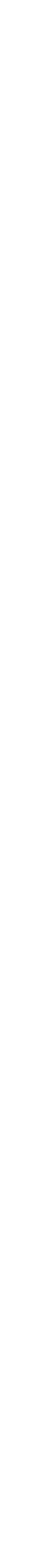

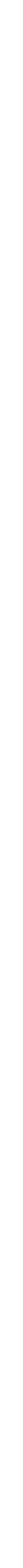




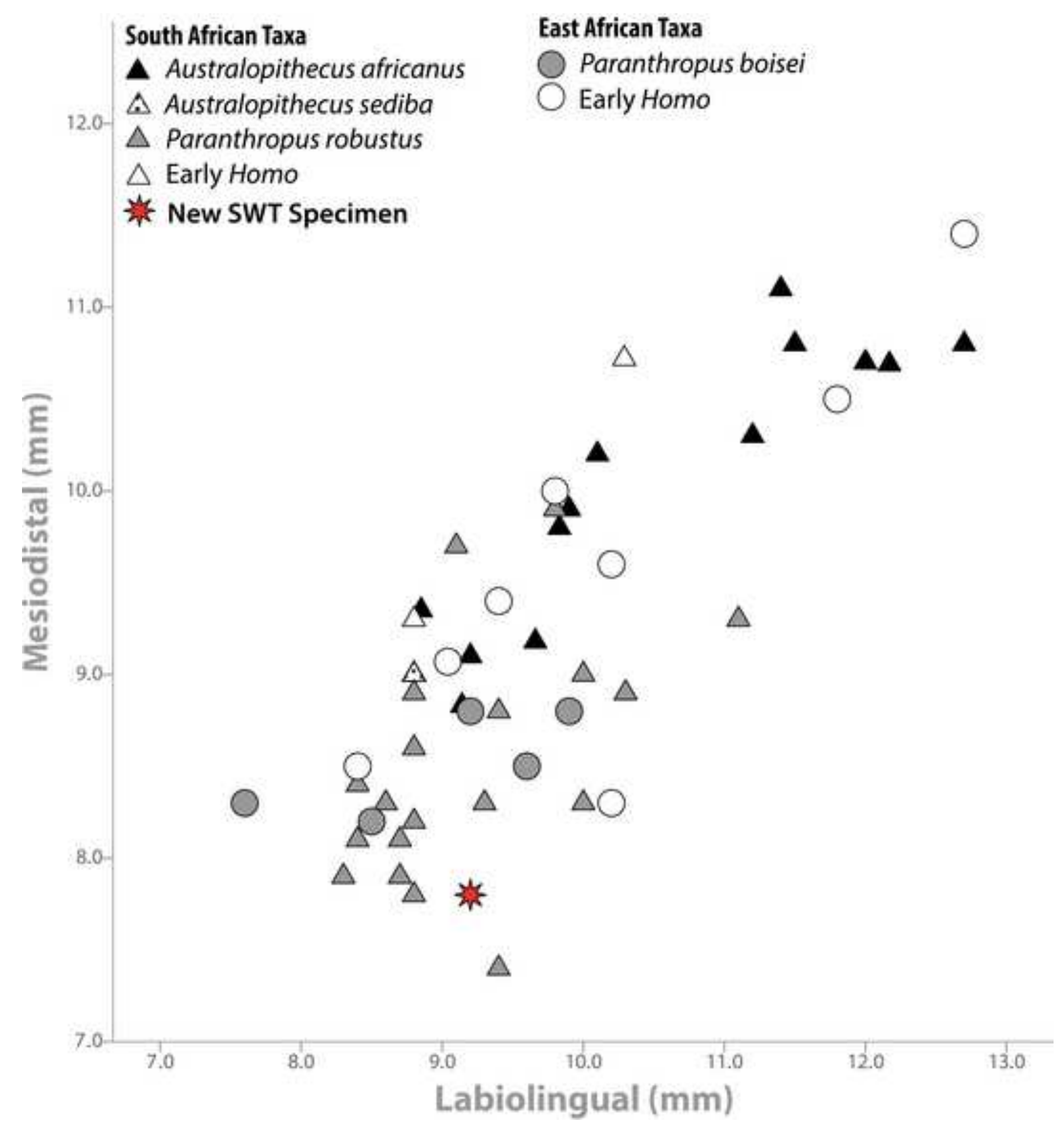




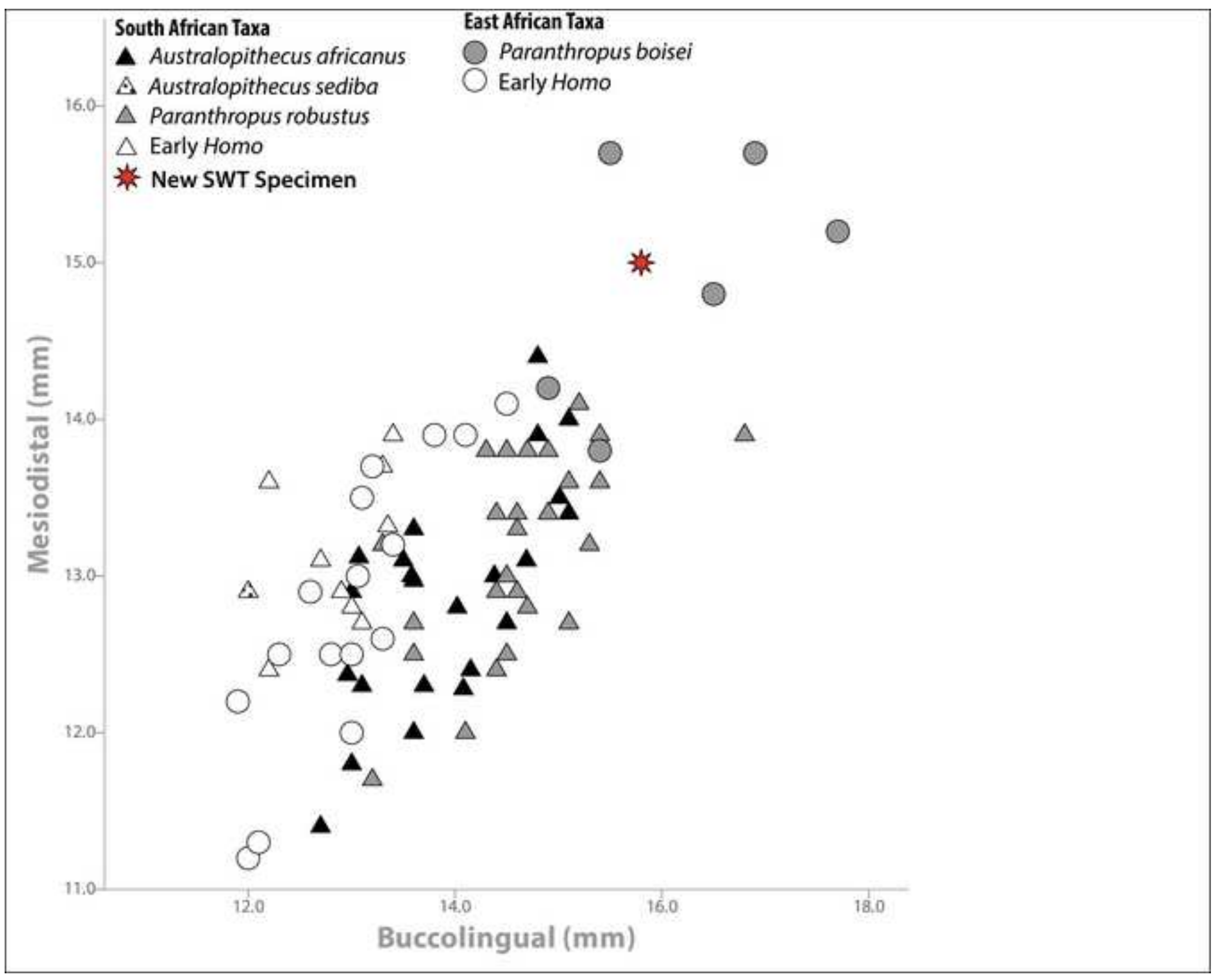




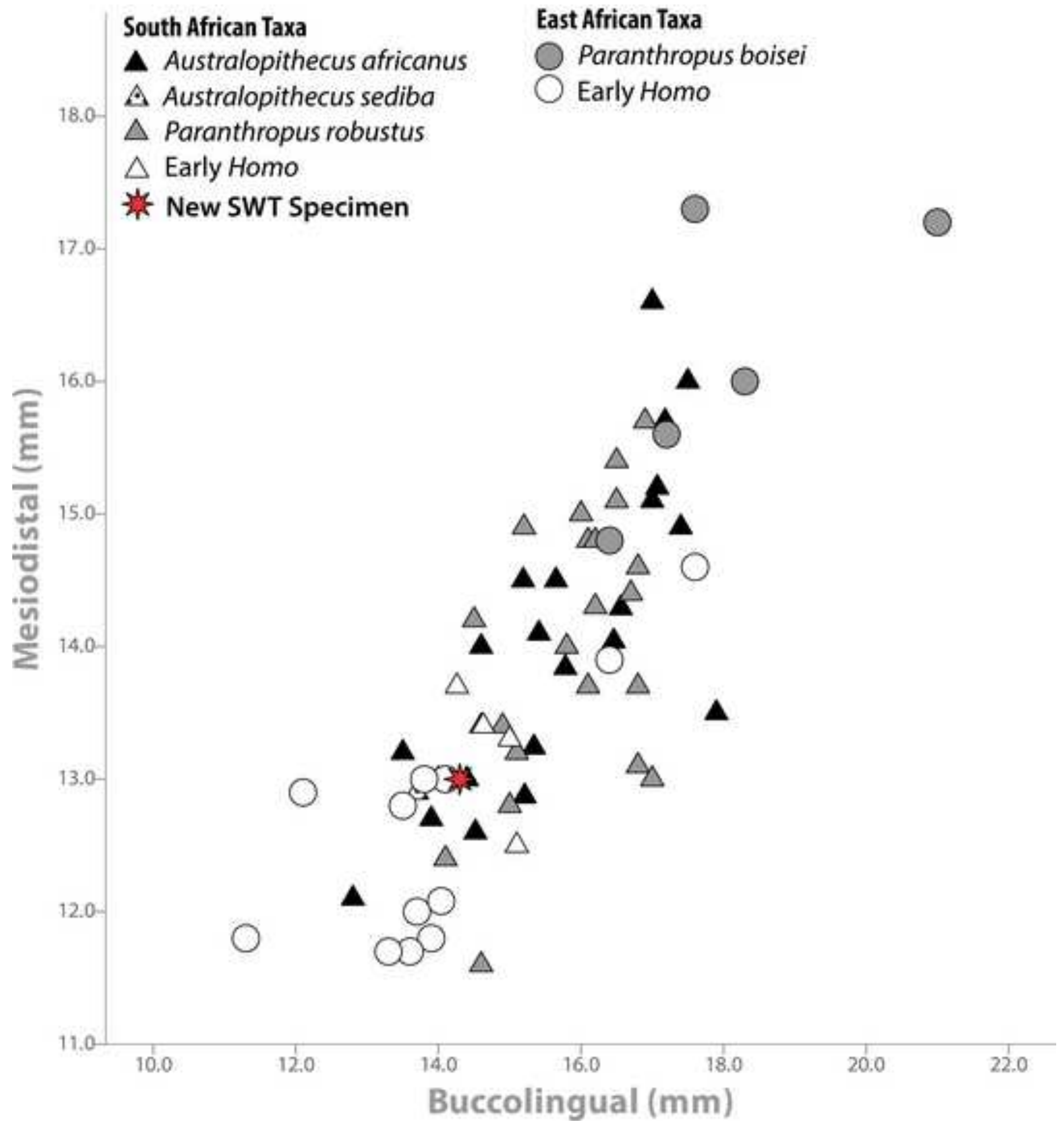

A Australopithecus africanus

$\triangle$ Australopithecus sediba

$\triangle$ Paranthropus robustus

$\triangle$ Early Homo

New SWT Specimen$$
17.0
$$

11.0

\section{Buccolingual ( $\mathrm{mm}$ )}




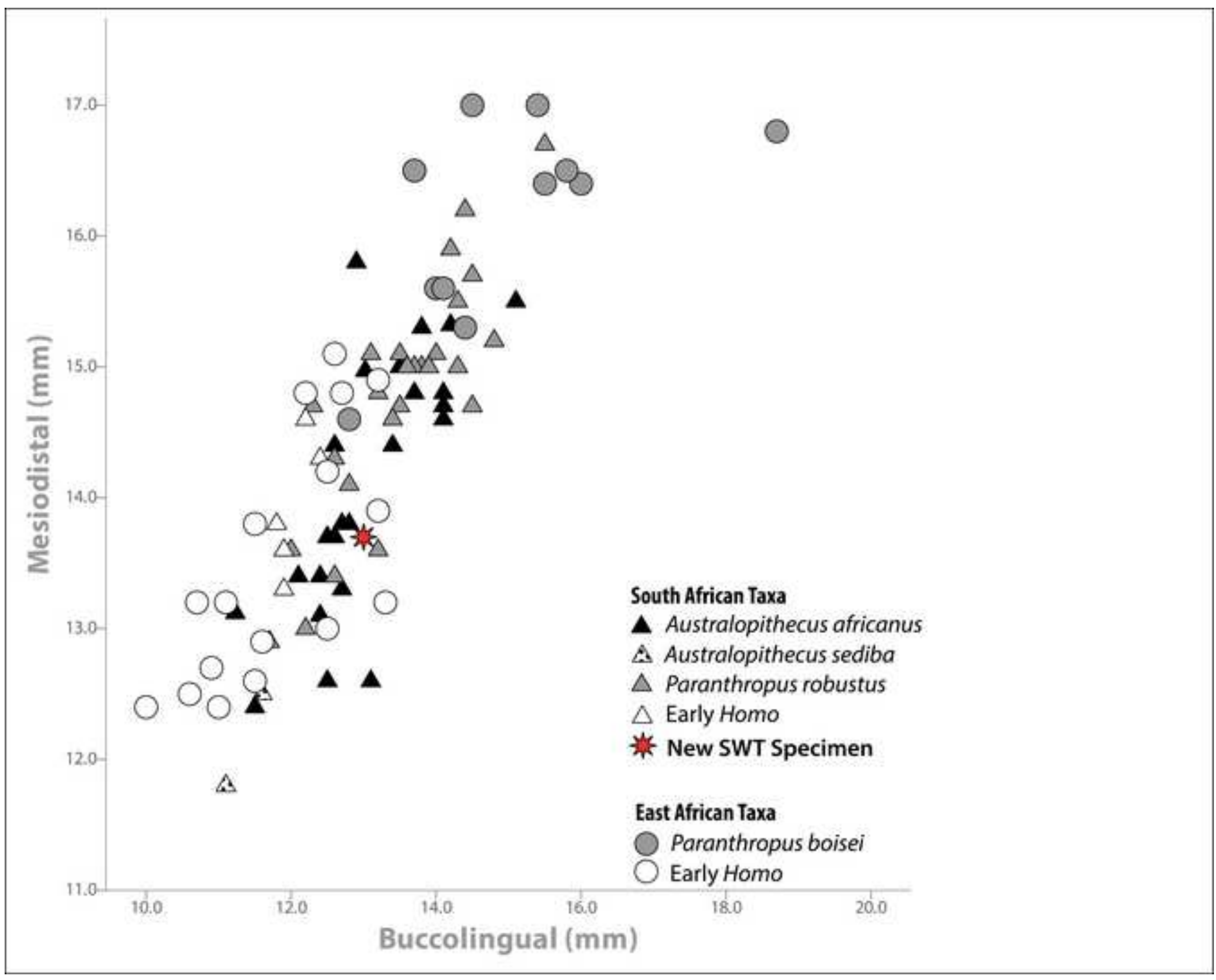

South African Taxa

$\triangle$ Early Homo

读 New SWT Specimen

East African Taxa

Paranthropus boisei

Early Homo

\section{Buccolingual (mm)}




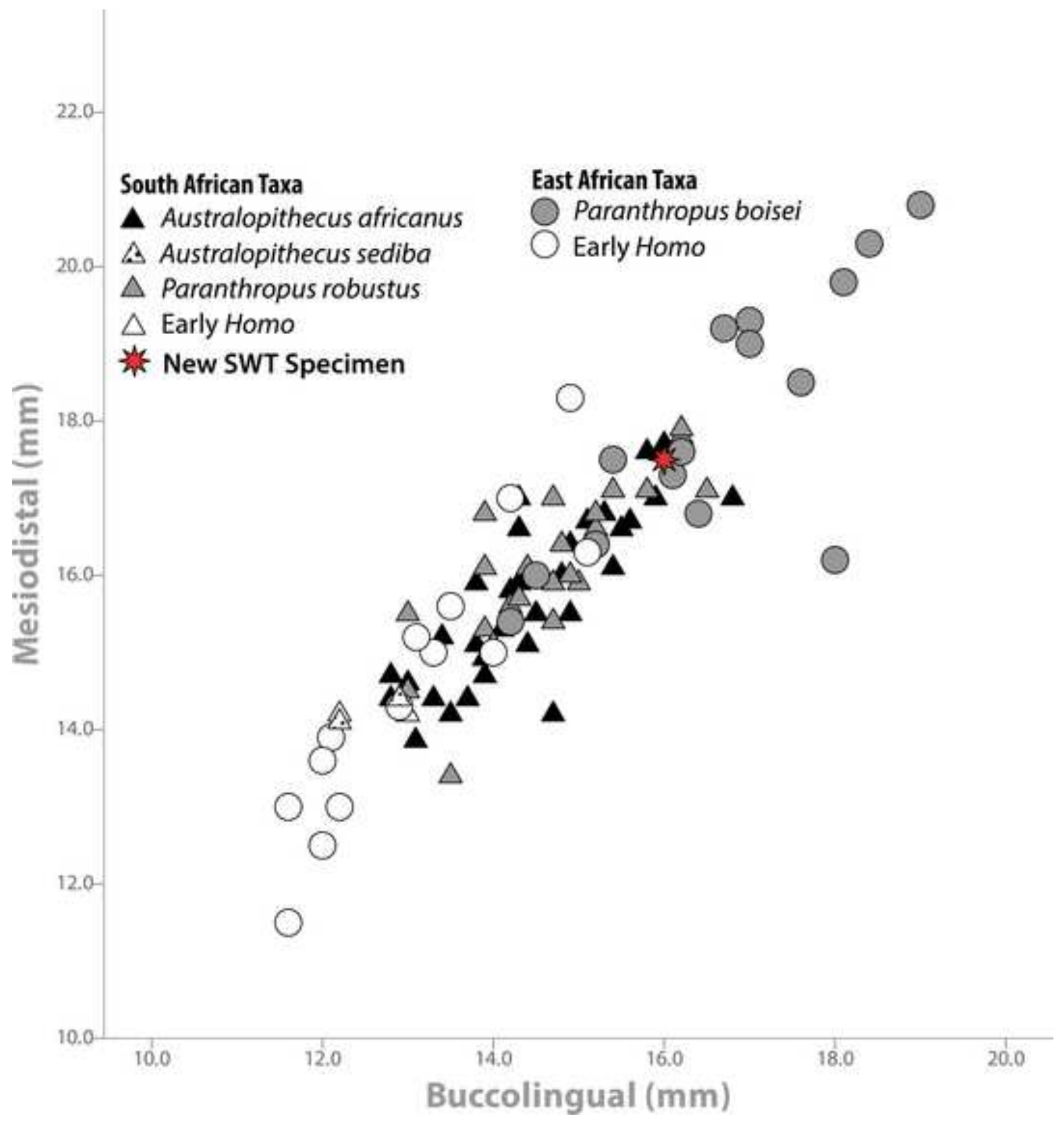

South African Taxa

Australopithecus africanus

Australopithecus

Paranthropusrobustus

$\triangle$ Early Homo

㨁 New SWT Specimen

a

$\triangle$

0

\section{East African Taxa \\ - Paranthropus boisei \\ Early Homo}

D)

12.0

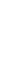




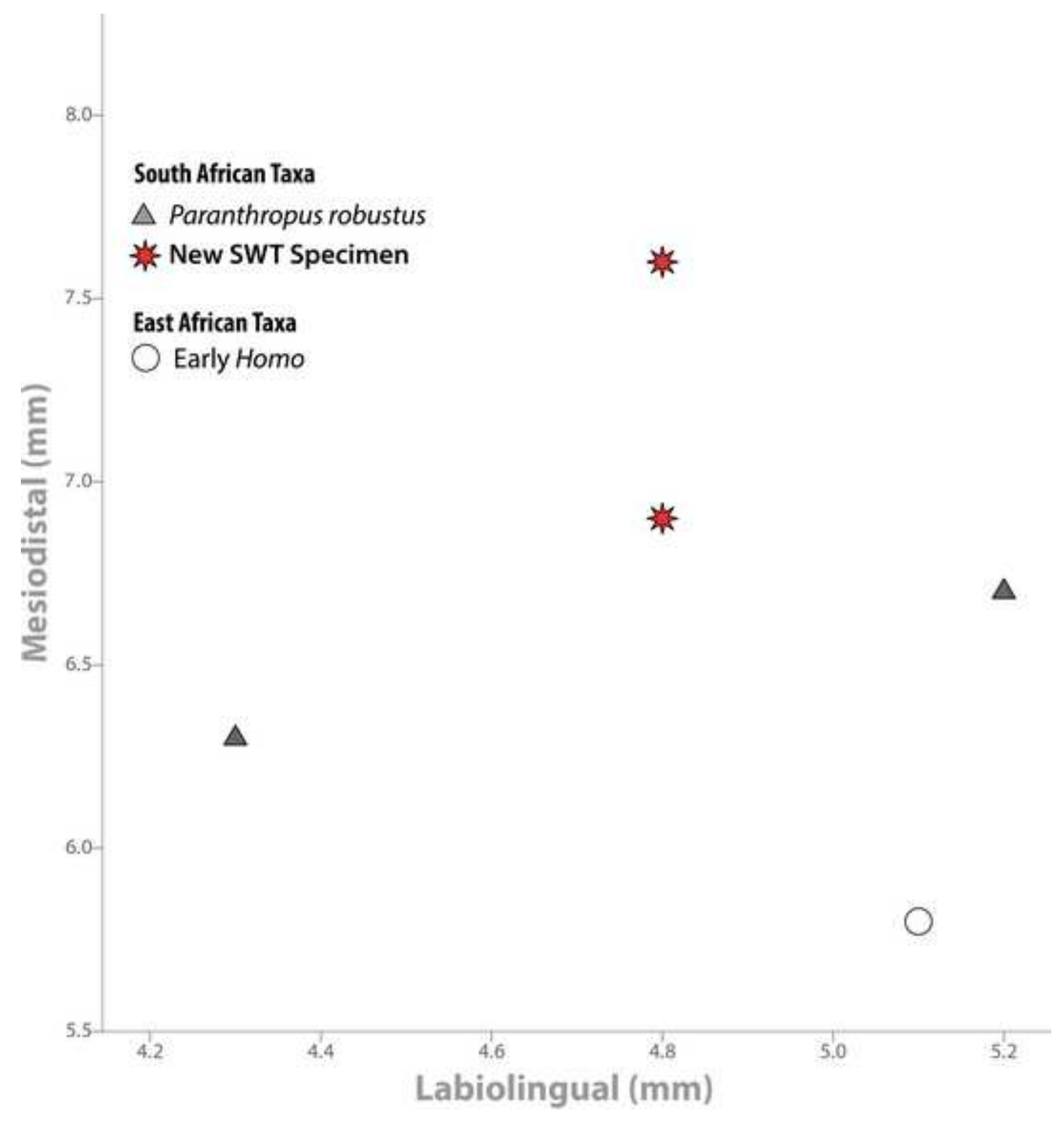

Figure

South African Taxa

* New SWT Specimen

East African Taxa

Early Homo

\section{然}

6.5

$\triangle$

6.0

Labiolingual ( $\mathrm{mm}$ )

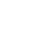




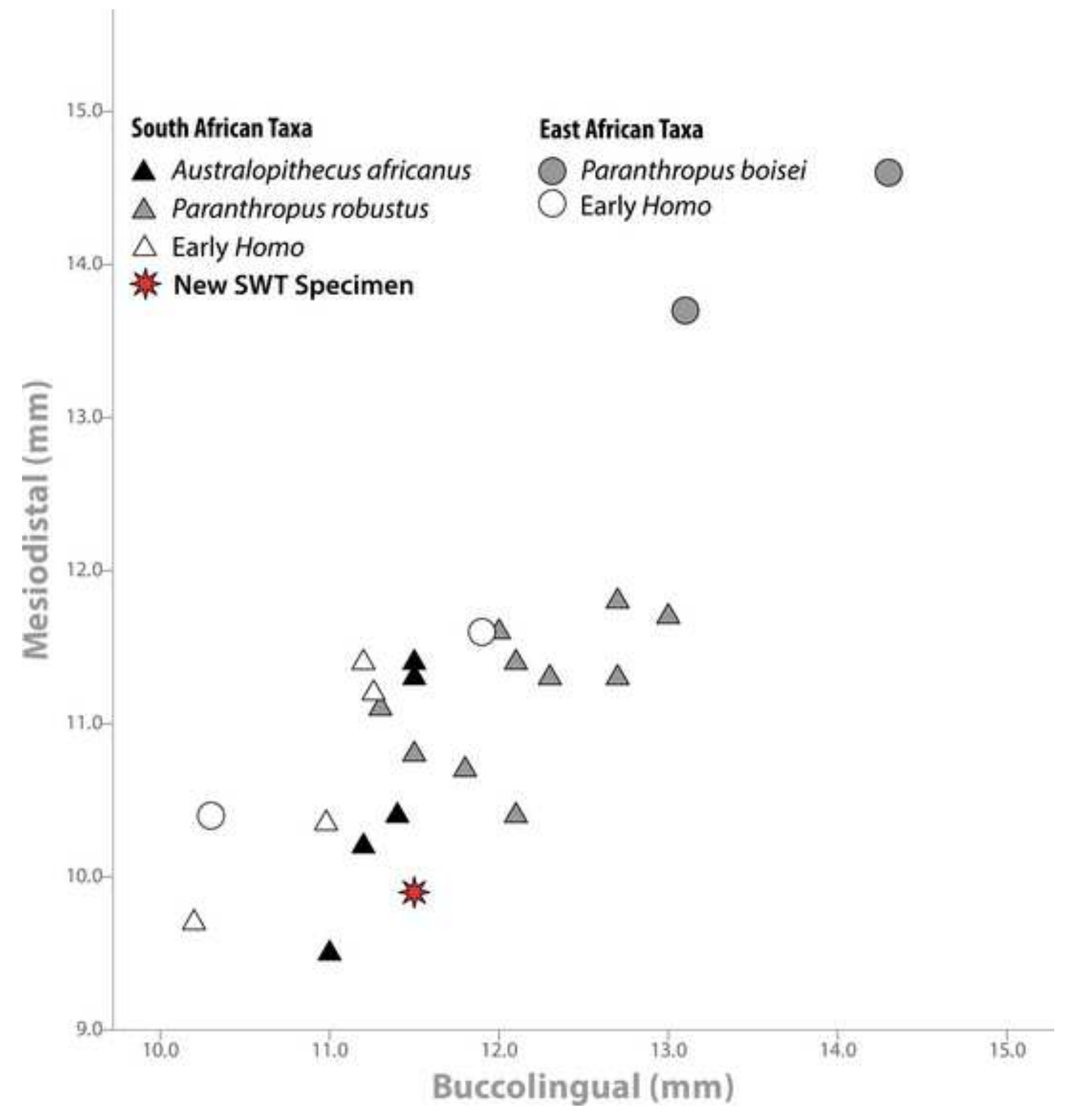

- Australopithecus africanus

Paranthropus robustus 谈 New SWT Specimen

Paranthropus boisei
Early Homo

Paranthropus boisei
Early Homo

East African Taxa

South African Taxa

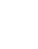
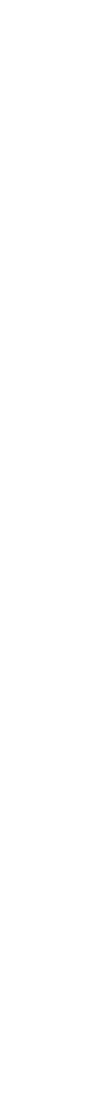

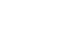

(1) 